Portland State University

PDXScholar

Spring 7-25-2013

\title{
Economic Inequality's Correlation with Political Inequality and Inequality of Opportunity and the Implications for Social Justice Theory
}

Staci Leigh Schoff

Portland State University

Follow this and additional works at: https://pdxscholar.library.pdx.edu/open_access_etds

Part of the Inequality and Stratification Commons, Political Theory Commons, and the Politics and Social Change Commons

Let us know how access to this document benefits you.

\section{Recommended Citation}

Schoff, Staci Leigh, "Economic Inequality's Correlation with Political Inequality and Inequality of Opportunity and the Implications for Social Justice Theory" (2013). Dissertations and Theses. Paper 980. https://doi.org/10.15760/etd.980

This Thesis is brought to you for free and open access. It has been accepted for inclusion in Dissertations and Theses by an authorized administrator of PDXScholar. Please contact us if we can make this document more accessible: pdxscholar@pdx.edu. 
Economic Inequality's Correlation with Political Inequality and Inequality of Opportunity and the Implications for Social Justice Theory

\author{
By \\ Staci Leigh Schoff
}

A thesis submitted in partial fulfillment of the

Requirements for the degree of

Master of Arts
In
Political Science

Thesis Committee:

Craig Carr

Christopher Shortell

Bruce Gilley

Portland State University

2013 
(C) 2013 Staci Schoff 


\begin{abstract}
In 2004 the American Political Science Association ("APSA") published research exploring whether the rising income inequality in the United States had an effect on political equality. Although the APSA found tremendous evidence of a correlation between income and political power, the APSA nonetheless concluded that the issue could not be conclusively determined without further analysis.

The intent of this thesis is to argue the position that economic inequality is heavily implicated in both political equality and equality of opportunity, and to propose a political theory that directly addresses- rather than evades- this issue. A conclusion drawn in this paper is that it is necessary in liberal capitalist environments to place constraints on individual economic liberty for the sake of maintaining some degree of economic equality. I show in this paper that this conclusion is consistent with both the liberal tradition and American political culture.

This paper accepts - rather than circumvents- the fundamental principle that income inequality is inevitable in a capitalist democracy as is the ability of money to purchase positions, power, and assorted privileges. Therefore, it should be the goal of social justice theory to ensure the gap between the richest and poorest be allowed to be great enough to respect individual choice and responsibility, but not great enough to dampen the opportunities available to those born into the bottom of the economic scale or to permit those born into the top of the economic ladder to exert oppressive power over the rest.
\end{abstract}


In the final chapter I propose four methods of narrowing economic inequality. These include a minimum standard, minimum wage and income tax reform, a tax and cap on wealth and an absolute inheritance cap. These four methods of limiting economic inequality are directed at narrowing, if not eliminating political inequality and inequality of opportunity. 
Table of Contents

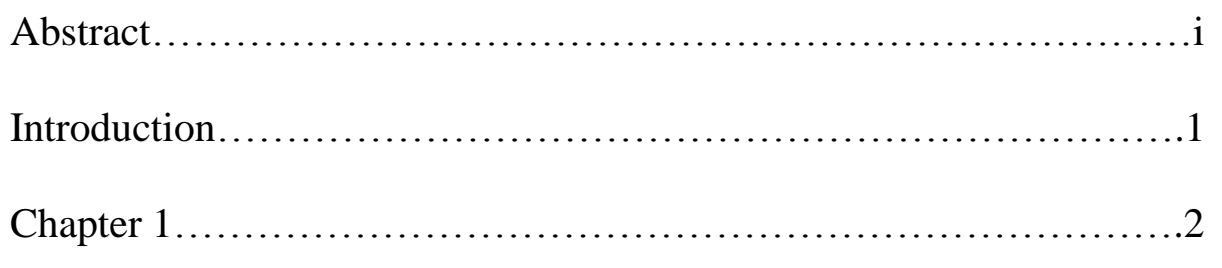

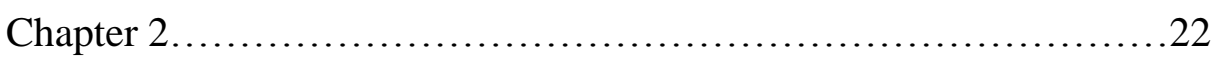

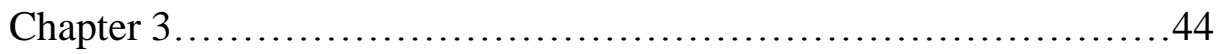

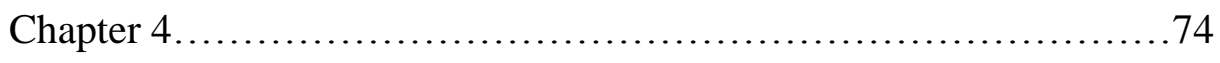

Conclusion................................................ 82

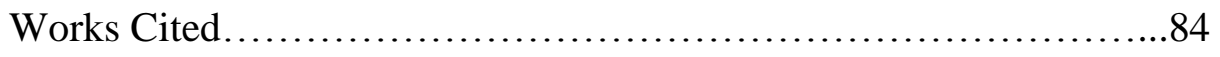


Introduction

A social justice theory can bubble out of the natural law tradition, in which one can make the case, as many have, that either God or Reason can tell us what is required of us according to the laws of nature. Social justice can also be conceived of as an issue of ethics after the fashion of Ronald Dworkin. Regardless of how we conceptualize it, this paper is directed at illustrating that fair and equal treatment for all citizens matters in a liberal society and will conclude that where there is vast economic inequality, individual liberty and political freedom are impinged upon. My intent for this paper is to argue that vast income inequality correlates with political inequality - defined as the power to create and amend policies that affect you - and inequality of opportunity over time. Regardless of the conditions and constraints upon how those inequalities develop, they must be moderated if we are to obtain political equality. For purposes of this paper, I will assume that some degree of wealth inequity must be permitted for the sake of individual liberty in a liberal culture such as the United States. 


\title{
Chapter 1
}

The Correlation Between Income Inequality, Political Inequality and Inequality of Opportunity in the United States

\begin{abstract}
In chapter one, evidence is explored that suggests a correlative, if not causal relationship between income inequality and political inequality, and that income inequality has become so great in the United States so as to be a direct threat to equality of opportunity and political equality. This chapter illustrates this contemporary problem facing the United States and begins the process of looking at possible ways to address it. It is the foundation for the conclusion of this paper.
\end{abstract}

Introduction

In 2004 the American Political Science Association assembled a task force to examine three possible indicators that rising income inequality is implicated in rising political inequality. The task force looked at "citizen participation, government responsiveness, and patterns of public policy making" (American Political Science Association 2004). The task force found that not only has the gap between rich and poor increased, so has the gap between the rich and the middle class. Still, the task force concluded that there is little evidence that rising income inequality has a direct effect on widening political disparities, but admitted that it is a point of concern that requires further analysis (APSA 2004). I will attempt to illustrate in this chapter that subsequent research has produced the missing information - that indeed there is now plenty of evidence indicating that income inequality is strongly implicated in political inequality, and a direct threat to equality of opportunity. 
The most compelling analysis of this issue is that offered by Jacob Hacker and Paul Pierson in their book, Winner-Take-All Politics. In it, they illustrate both how political policy has created this increasingly non-egalitarian income and wealth distribution as well as how the resulting non-egalitarian income and wealth distribution has created a political inequality that makes change and reform seem a daunting task at best. They offer an assessment of how Republicans and Democrats have contributed in different ways, due to differing ideologies, to the disparity (Hacker and Pierson 2010, 168-170). They go beyond partisan politics and discover how the richest among us have not just been influential in affecting economic policies that benefit them, but have essentially co-opted the political system - they have not just managed to "get richer" as has always been typical - wealth generally begets wealth - but they have successfully restructured, "the economy to shift the risks of their new economic playground downward, saddling Americans with greater debt, tearing new holes in the safety net, and imposing broad financial risks on Americans as workers, investors, and taxpayers" (Hacker and Pierson 2010, 13). Hacker and Pierson's assessment is relied upon heavily for the conclusions drawn in this chapter.

This section will outline the manner in which politics has created and reinforced rapidly rising income inequality and how that has both led to and increased political inequality and inequality of opportunity. Finally, I will examine some possible remedies for combatting this disturbing trend. 
Statistics on Rising Income Inequality in the United States

There is little dispute that as compared to the post-war era through the 1970s, the 1970s forward have shown a tremendous increase in the disparity in income growth among the upper, middle and working classes. During the period of 1947-1973 family income growth among the lowest quintile increased by 115 percent, the middle quintile increased by 97.7 percent and the top quintile increased by 84 percent. By contrast for the years 1973-2000 family income growth among the lowest quintile increased by 10.3 percent, the middle quintile increased by 24.1 percent and the top quintile increased by 61.6 percent (APSA 2004). It could be argued that the lowest quintile still saw an increase in income and that the top quintile also saw less of an increase in income; however, there is evidence to support the notion that the real income of working class Americans has declined over this period, when benefits and such are factored in, that we will examine a little bit later - while the top quintile became substantially better off. Finally, during the years 2000-2005 income growth decreased for all groups, but by the greatest percentage among the lowest quintile. Real family income growth fell by nearly 8 percent among the lowest earners and 0.9 percent among the highest earners (Jacobs and King 2009, 17). A rapid change in economic distributive patterns has clearly occurred - this paper accepts that as a fact and point of departure. ${ }^{1}$

\footnotetext{
${ }^{1}$ The APSA's analysis attempts to show that since the 1970s the United States has become more egalitarian in terms of race and gender and simultaneously less egalitarian in terms of income. However, while it may be true that overt inequalities based on gender or race have lessened, Blacks and Latinos both are still more likely to be working class as well as more likely to be at the bottom of whatever class they belong to. For all of the alleged progress America has made regarding racial inequality since desegregation and the Civil Rights Movement, during the 1980s the income gap between Whites and Blacks returned to 1950s levels. (APSA 2004) Indeed black married couples in
} 
Additionally, the richest 1 percent's share of the national income has risen steadily since the Carter Administration, implicating changes in long-term policies that allowed for the vast gains under Republicans and Democrats alike. Even modest income growth among the working and middle classes have largely been due to increased work hours - all the while, since the 1970s employers have steadily decreased benefits (Hacker and Pierson 2010, 26, 30). While the United States economy experienced astronomical growth overall, the majority of Americans went further into debt, worked more hours for the same pay, lost benefits and found that the potential for social mobility has fallen drastically (Hacker and Pierson 2010, 2633).

History and Possible Causes of Increasing Inequality

The standard explanation for the dramatic rise in income and wealth inequality in the United States since 1973 (as opposed to the more egalitarian growth patterns during the post-war period) generally rests on a theory of inevitability due to the globalization of the economy and rapid technological advancement (Bartels 2008, 17). This explanation, however, fails to tell the whole story. The most obvious problem with the story is that market globalization and rapid technological advancement have occurred globally, and other wealthy democracies - Canada and most western European countries - have managed to maintain a more egalitarian income and wealth distribution structure. This section income and possess 80 percent less net worth. (Jacobs and King 2009,20) This is an important point of interest, but unfortunately beyond the scope of this paper. 
will examine some of the policies and tendencies in the United States that have contributed to rising inequality and the decreased social mobility that goes hand in hand with inequality of opportunity. In the United States "most of the shift in the income distribution has been from the bottom 90 percent to the top 5 percent." This suggests that "power relations" not just "market forces" is a likely suspect (Bartels 2008, 17).

One possible answer to the economic problems facing the United States is partisan politics. The Republicans cater to the rich and the Democrats cater to the poor is a popular sentiment. However, it's not as simple as that. In fact Democratic Presidents Jimmy Carter and Bill Clinton signed into law most of the policies that have been implicated in the U.S. financial crisis as well as rising inequality, even while Congress was controlled by the Democrats during the first two years of Bill Clinton's presidency and the entire four years of Carter's term (Jacobs and King 2009, 7-9). These policy shifts will be examined in detail in another section of this chapter. For now it is important to note that electing the "right" person to office is not necessarily the cure - the presidency of Democrat Barack Obama, who was elected in an atmosphere of hope that it might be, is a good example of how small a piece of the puzzle the president actually is. Obama has, with few exceptions, essentially carried on the policies of the Republican administration that preceded him - by all accounts, those policies don't necessarily reflect Obama's desires or personal beliefs, but for a variety of troubling reasons, they remain. The most obvious reason is the basic structure of the United States' constitutional government - bicameralism, separation of powers and federalism all place constraints upon the 
power of political officials to enact policies even when said policies appear to have popular support (Shapiro 2003, 109-110). The tale of rising inequality shows both parties are responsible for agenda setting in Washington and both are implicated (Hacker and Pierson 2010, 168-169). As Bartels demonstrates, however, Democrats do a better job of maintaining a semblance of egalitarianism than do Republicans:

"On average, the real incomes of middle-class families have grown twice as fast under Democrats as they have under Republicans, while the real incomes of working poor families have grown six times as fast under Democrats as they have under Republicans" (Bartels 2008, 3).

Additionally, the real value of the minimum wage has risen significantly under Democrats but fallen significantly under Republicans (Bartels 2008, 226). Partisan politics obviously matters, but both Democrats and Republicans presidents and legislators - are still obliged to operate in an atmosphere of indebtedness to corporate wealth, rendering non-egalitarian policies and trends a much deeper political issue than simply choosing one side over the other. Because campaign contributions are necessary for the success of both parties, Democrats are just as likely to be "especially responsive to the views of resource-rich constituents, notwithstanding the historical association of the Democratic Party with the political interests of the working class and the poor" (Bartels 2008, 268). Furthermore, the deregulatory policies and tax cuts, that have accelerated the disparity in income and wealth, have been implemented with the support of Democrats, not surprising given that the majority of the billions of dollars spent every year on politics isn't spent on 
election campaigns, but on lobbying - "sustained, intense efforts to shape what happens in Washington" (Hacker and Pierson 2010, 114). These sustained lobbying efforts by wealthy corporations have a tremendous disparate impact on policy making that is unavailable to non-profit groups and individuals. The number of registered corporate lobbyists in Washington grew from 175 in 1971 to 2,500 in 1982 and the number of "corporate PACs increased from under 300 in 1976 to over 1,200 by the middle of 1980" (Hacker and Pierson 2010, 118). These characters have been the most influential on government policy makers both by virtue of money and proximity - these are the people who ultimately have the ear of lawmakers - both Democrat and Republican.

One of the most basic economic policies contributing to the rise in inequality is that governing the federal minimum wage. Again, in defiance of broad public support for a rising minimum wage that keeps pace with inflation and despite its increase in real value during the 1950s and 1960s, "the real value of the minimum wage has fallen by almost 45\% since the late 1960s" (Bartels 2008, 224). Raising the minimum wage is often condemned as reducing employment opportunities, but there is little evidence to support that thesis (Bartels 2008, 227). The falling value of the minimum wage is strongly implicated in the increasing income gap between rich and poor, and one possible reason for the decline in the minimum wage is the simultaneous decline in union membership (Bartels 2008, 226, 240). As business organized more strongly and injected more capital into Washington, they were able to use the Taft-Hartley Act to shift their operations to right-to-work states and 
employers became ever more brazen in violating fair labor standards and blocking union organizing (Hacker and Pierson 2010, 128).

While this information may be troubling in general, the most disturbing point for the purpose of this paper is that the overwhelming majority (in some surveys, more than seventy percent) of Americans are in favor of minimum wage increases that keep pace with inflation - in some surveys "supporters have outnumbered opponents by margins of about four to one" (Bartels 2008, 226). Clearly something other than democracy is at work here. It's not just the minimum wage, as government policy does not reflect public opinion on education, healthcare or defense spending either (Jacobs and King 2009, 146-147). The following observation is a good prelude to the discussion on oligarchy and political equality that follow later in this chapter, as it is illustrative of a political policy that increases economic inequality and continues, contrary to public opinion:

A conservative minority has been able to block substantial increases in the minimum wage, even when the Democrats had unified control of Congress under Jimmy Carter and in the early Clinton administration. Therefore, the real minimum wage has fallen... However, it begs the question of why minimum wage rates have been set in nominal dollars. After all, many other federal benefits and income thresholds are automatically adjusted to take account of inflation (Bartels 2008, 234).

The best explanation for the dramatic increase in inequality since 1973 is what Hacker \& Pierson label "drift." They assert that in addition to big changes in positive law, government nonresponse to dynamic economic conditions is the major way in which politics has exacerbated income inequality (Hacker and Pierson 2010, 
43). To explore this we'll look at both changes in positive law and the lack of changes that worked together to create inequality. Accepting as fact that the "free" market does not operate independently of government - government rules and lack of rules shape the market - this exploration of policy will hopefully illuminate a path to reversing the vast disparity that threatens our political ideals (Hacker and Pierson 2010, 44, 82).

Some very basic policies have clearly contributed to rising inequality. The main areas of concern are taxation, "government's treatment of unions, the regulation of executive pay, and the policing of financial markets" (Hacker and Pierson 2010,56). And contrary to popular sentiment the problem didn't start with the Bush tax cuts, nor did it start with "Reaganomics." The initial change in policy that led to a dramatic redistribution of wealth upward began with Jimmy Carter. Under Carter (and a Democrat-controlled congress) a proposal to prevent future erosion of the minimum wage - by tying it to the manufacturing wage - was defeated, as was a proposal to update outdated labor relations laws and a health care reform proposal. What was passed was a tax bill that sharply cut the capital gains tax - which only benefits the wealthy, while simultaneously raising payroll taxes - which adversely affects workers and small business owners (Hacker and Pierson 2010, 99). This set the stage for 1981 when the devastating Economic Recovery and Tax Act was passed reducing even further the capital gains tax, the estate tax and taxes on corporations (Hacker and Pierson 2010,134). In the 1950s corporate income tax accounted for 30 to 40 percent of federal revenue, but by 2007, even with record profitability corporate income taxes fell to 14.7 percent of 
total federal revenue. At the same time payroll taxes went from 8 to 10 percent of federal revenue to 35 to 40 percent (Jacobs and King 2009, 159).

One clear example of the concept of drift is the Financial Accounting Standards Board's attempt to regulate CEO compensation in the early 1990s. Corporations began awarding stock options to CEOs that were not tied to long-term performance and were not written off as an expense for accounting purposes. The FASB saw a number of problems with this, primarily a lack of transparency, and proposed reform. Business interests joined together, badgered the Chair of the SEC, and ultimately, with the help of prominent Congressional Democrats, ensured its defeat (Hacker and Pierson 2010, 246-247).

Income Inequality Creates Inequality of Political Power

The essential point is that where the possession of political power is due to the possession of economic power or wealth, whether the number of persons be large or small, that is oligarchy, and when the unpropertied class have power, that is democracy (Bartels 2008, 284).

In "Oligarchy in the United States" Jeffrey Winters and Benjamin Page make the case that it is plausible to conclude that the United States may be an oligarchy even as it is a democracy (Winters and Page 2009). Defining oligarchy as a specific kind of minority power that is material in nature, they posit that the oligarchy may coexist with democracy, defining and limiting it without abolishing it entirely. They assert that wealth is not just a major source of political power, but is rather the most important source of power concerning economic policies. This power then is used 
by the very wealthy to maintain their wealth and yet other issues that don't affect economic status are then left to the democratic process. This is illustrated in a couple of different ways. First, the article asserts that there is evidence that the policies that affect the wealthy, such as taxation, international business, finance regulations and redistribution of wealth do not reflect public opinion on said matters (Winters and Page 2009). In support of this they point out that an analysis of the roll call votes of Senators indicates they tend to vote in line with the opinions of their wealthiest constituents rather than the majority of their constituents. Larry Bartels uncovered the same phenomena pointing out that the opinions of those at the bottom third of the income distribution scale were "entirely unconsidered" by their representatives (Bartels 2008 253-254).

Winters and Page use income and wealth based power indices to show that the greater one's wealth the smaller number of people one needs to agree with him/her on a political issue. By contrast those with the least wealth need to rely on vast coalitions of like-minded people to have any affect on the political process at all. In other words one person with a lot of money can affect the political system as effectively as a great coalition of people with no money (Winters and Page 2009). Their conclusion is that the top one-hundredth of one percent of the wealthiest Americans has 463 times the individual power than an individual in the bottom 90 percent (Winters and Page 2009). The source of this power can be overt such as lobbying efforts and constitutional protections of wealth and also take more subtle forms, such as opinion shaping and electoral impact which is increasingly controlled by money (Winters and Page 2009). When this extreme political power is 
concentrated among such a small minority of the wealthiest individuals, it is difficult not to concede that it looks an awful lot like oligarchy.

Further support for the idea that oligarchy coexists with democracy in the United States is the quandary of "why don't the $50.1 \%$ of the people on the lower end of the income scale raise taxes on the upper $49.9 \%$ at will?" It may be due in part to cultural phenomena such as belief in the ability to become rich one day even if poor now, skepticism of government's ability to effectively run social programs, the two-party system - both of which advocate more or less of the status quo, and a tendency to compare the U.S. capitalist system to the economic disaster that was communism in the Soviet Union rather than compare it to the socialist democracies on display in western Europe (Gelman 2008, 139-140). Another possibility is that when judging the fairness of a system people tend to compare themselves to those who are similarly situated to them, not to those who are far more or far less well off then they are (Shapiro 2003, 119-121). However, these are not adequate explanations in light of the tendency of the poor to support the Democratic Party, which is slightly more supportive of wealth redistribution and social welfare policies (Gelman 2008, 3). Also, if it is true that the wealthy ruling class has a great deal of power over swaying public opinion, then it might be that what the press reports people think or what the politicians assert the people value in their speeches is suspect. There are a lot of wealthy, older, white people in Arizona, for instance - a Republican voting demographic - therefore Republicans tend to win elections in Arizona. Given the low voting rates of poor people, the high voting rates of older, white and wealthier people, and the large number of resident and non- 
resident aliens in the state, one can hardly conclude that the majority of people living in Arizona likely believe that the wealthy should not be subject to increased taxation or that Chevron should be subsidized by tax-payer money, while individuals are left to their own devices. Yet, "Arizonans overwhelmingly believe..." is what is heard in the news. American citizens' devotion to individual liberty does come into play, but it's not an adequate explanation for the excessive economic inequality that has developed over the past four decades. In fact, recent surveys show that most Americans in general are in favor of government programs that reduce economic inequality (Jacobs and King 2009, 135).

Another commonly touted belief is that the working poor are voting for Republican candidates against their own economic best interest due to devotion to certain conservative social issues. However, statistics don't bear this out. The working poor tend to be primarily concerned with the economic issues that affect them directly - if anything the working poor have become more devoted to the Democratic Party (Bartels 2008, 67). Further evidence suggests that contrary to the caricature of the uneducated poor person who votes republican due to homophobia or other culturally conservative issues, the reality is the low income voters tend to vote primarily on economic issues. It is the upper -income voters who have the luxury of time and excess funds to worry about maintaining some sort of cultural status quo (Bartels 2008, 87).

The answer appears to be political rather than cultural, economic or technological. A possible response to the question of why Republicans win elections when common sense would suggest the Democrats have numbers on their side is 
offered by Larry Bartels. According to Bartels, voter behavior can be tied to the cycles of economic growth during the incumbent's presidency. He suggests that Democrats may be better at generating income growth overall, but Republicans are better at doing it during the election year and that voters have a short attention span which leads to the rewarding of the Republican Party and punishment of the Democratic Party (Bartels 2008, 104-109). ${ }^{2}$

The analysis presented by Bartels suggests that voters gave Democratic presidents no electoral credit for consistently producing stupendous income growth in the second years of their four-year terms (ranging from $4.0 \%$ for upper-middleclass families to $5.7 \%$ for the working poor), while Republican presidents have paid no electoral cost for consistently presiding over declines in real income for middleclass and working poor families in the second years of their four-year terms (Bartels 2008, 109).

What Happens to the Ideal of Political Equality

The APSA taskforce concluded that among those with income under $\$ 15,000$ per year, only half vote. By contrast, among those with an income of over $\$ 75,000$ per year, nine-tenths vote (APSA 2004). Voting is the most basic, easiest and one could argue least effective or important method of political participation, but it is a common benchmark used to determine public opinion and degree of apathy. In

\footnotetext{
2 Even if not personally identifying with one party or the other, the republicans' ability to look better at the end of four years than the democrats generally do has an effect on re-election. One possible explanation to consider is that the democrats' method of generating income growth requires the cooperation of republicans, who can strategically block their efforts at opportune times.
} 
addition those in the lower income bracket are less likely to be affiliated with a political organization, serve on boards, protest, be involved in other community activities or make campaign contributions. The task force suggests that the reason the working poor don't vote is because they lack the skills and they are not motivated (APSA 2004). But there are several other possible reasons for this. First, the working poor are less likely to view their immediate economic circumstances as tied to any particular administration - those without 401K's and homes and such are not as likely to follow the musings of the Federal Reserve Chairman, for example. The working poor may be aware that they're less likely to be listened to by politicians and may be more likely to view one as bad (or good) as the other. Additionally, lower income jobs offer less flexibility, so they may just be less able to make it to the polls.

In terms of public opinion, the media pay a great deal more attention to the economic concerns of stockholders and homeowners than to the concerns of the very poor (Bartels 2008, 116). But even those in a lower-income bracket see their fate as entrenched with the fate of the wealthier classes. They may not be worried about the stock market in terms of a personal portfolio, but they are worried about the availability of jobs, quality of education, gas prices and $\operatorname{such}^{3}$ (Bartels 2008, 125). The unfortunate result of all this is that an examination of Senator roll call votes both on economic and social issues indicates that the "bottom third of the

\footnotetext{
3 That some low-income voters buy the republican story of the necessity for low taxes on corporations in order to stimulate job creation might be a better possible explanation for the minority of those that do vote republican than the idea that they are voting based upon social rather than economic issues.
} 
income distribution received no weight at all in the voting decisions of their senators," whereas the senators are slightly more responsive to middle income earners and "quite responsive" to the opinions of their constituents in the top tier of the income distribution (Bartels 2008, 254, 260, 265, 267). Even worse, "when the poorest people in a state support a policy, their senators are less likely to vote for it" (Hacker and Pierson 2010, 111).

Possible Remedies Involve Inequality of Opportunity American culture more readily accepts economic inequality than their European counterparts for a variety of reasons that are beyond the scope of this paper, but one American value that is held dear is the notion that regardless of one's background, everyone has the opportunity to become among the very wealthy. The pattern since the 1970s shows that the potential for class mobility has decreased to nearly nonexistent and this, rather than inequality itself might be the factor that finally mobilizes the American public to address the issue (APSA 2004). Surveys indicate that three-quarters of Americans believe that the rags to riches tale is still possible - which is true, there is about a $2 \%$ chance that someone born to the bottom tenth of the income scale will one day work their way to the top tenth (Jacobs and King 2009, 141). While the majority of Americans espouse a belief in egalitarianism, there appears to be a disconnect between a recognition of those values and a recognition of how income inequality actually affects real social outcomes such as social mobility, equality of opportunity and equality of political power (Bartels 2008, 161). The real lack of political equality exacerbates the 
challenges to the a path of reform - the lower-income and less wealthy classes are at a fundamental disadvantage in terms of ability to influence social policies that affect their opportunities to better their financial positions. It appears, given the ways in which increased inequality has come about, that it's possible to reverse these unfair economic trends, but it requires action on the part of those adversely affected, and people with lower incomes require greater coalitions to affect government change so it's not going to be easy (Winters and Page 2009).

Fortunately though, one recurring theme in all the works examined here is that there is hope in reversing the trend of inequality and the remedy is mobilization and organization among the working and middle classes. This is a little bit like saying the cure for obesity is to eat less and exercise more - everybody knows that, but that doesn't mean anybody's going to do it. Still several possible practical steps may have impact over time. If Hacker and Pierson are correct in their conclusion that it's American politics, not the changing economy or technological advancement determining this outcome, then the problem is manmade and there is hope for a remedy through political reform (Hacker and Pierson 2010, 300).

One of the most important ways that the working poor can affect their immediate outcomes is union participation, which has fallen by half since the 1970s. In addition to that various smaller organized groups need to create greater coalitions. But what do these organized groups need to do exactly? They need to seek reforms of the political and economic system that serve to redistribute the wealth downward rather than upward - tying the minimum wage rate to the 
average wage rate and tying CEO compensation to the long-term performance of the company are both important steps. Greater regulations of financial institutions, aggressively graduated tax policies that burden corporations and the very wealthy rather than the middle class and campaign finance reforms are also necessary measures. One thing that is clear, updated regulatory policies that reflect the changing business landscape are an indispensible part of effective reform (Hacker and Pierson 2010,257). This will be tricky given the American political system is designed to maintain the status quo and that American lawmakers tend to be from the upper class - this is why organization among the masses is so important (Hacker and Pierson 2010,113). Reform for the good of the poor, the working poor and the middle class has been accomplished in the past and surely can be done again.

One success story that may serve as a template for reform is the passing of the GI Bill. Spearheaded by the American Legion, a large coalition was formed (nearly 80 percent of young American men at the bill's passage were veterans of World War II) and through "mailings, petition drives, entreaties to local journalists, even a motion picture clip promoting the bill," ultimately lawmakers had no choice but to pay attention (Hacker and Pierson 2010,137-139). It appears that due to economic inequality and the resultant loss of political power among ordinary citizens that something like this can't be done again, but a large group of people with "the ability to pool and concentrate resources, develop expertise, and sustain focus" can wield political influence, even in light of present conditions (Hacker and Pierson $2010,139)$. The ability to organize appears to matter in terms of political outcomes, and this is where those with fewer resources are at a disadvantage. 
Conclusion

It should be clear at this point that political policy has been the primary culprit in the rapid rise in income disparity witnessed in the United States since 1973. It should also be clear that those on the losing end of those policies - the working poor and what remains of the middle class - are at a clear disadvantage should they attempt to affect political change. Thus illustrating that income inequality and political inequality go hand in hand. The notion that the government exists by and for the people is difficult to espouse in such an environment and selfgovernment - an indispensible value in the liberal tradition - is rapidly deteriorating. Broad coalitions of those devoted to maintaining a strong middle class and greater unionization of workers appears to be the most logical policydriven remedy.

A thriving capitalist economy demands strong government regulation and protections for workers so as to avoid the economic aristocracy that has emerged in the United States. The protection of employees in the workplace does not just benefit them economically, it preserves our political freedom and in turn political freedom is used to protect our individual and collective economic interests (Hacker and Pierson 2010, 298-301). As Franklin Roosevelt famously quipped, "political equality is "meaningless in the face of economic inequality" (Hacker and Pierson 2010, 306).

It's disheartening as it seems that a financial collapse rivaling that of 1929 or something more awful than a mass discontent among the majority of Americans who have lost ground financially may be necessary. Unfortunately, those most 
affected by wealth disparity are less capable of organizing for reform and those in the middle have just enough going for them that fear of losing what they have seems to override a collective desire to try to gain more - even when the status quo is viewed as unjust, there is a tendency in a formally egalitarian society to protect individual ability to achieve the "American Dream" than to focus on redistributive issues (Shapiro 2003, 122 -127). The more wealth a minority accumulates, the more affordable it is for them to appease the middle class with small incentives like tax breaks for education or mortgage interest, thus putting them in the position of fearing losing the privileges they have too much to collectively organize with the poor against the very wealthy few (Shapiro 2003, 139).

The research on boundary permeability thus suggests that modest tokenism may be sufficient to defuse pressure for collective redistribution, even when the status quo is seen as unjust" (Shapiro 2003, 123).

The median voter may also be affected by "downward-looking framing" which means they fear not just the poor, but becoming one of the poor - thus demonization of the poor as being lazy and such prevents the middle class from being able to relate to them (Shapiro 2003,131). More troubling is that the more one is alienated from the American Dream the less likely one is to seek change, even with nothing to lose.

...low status and a sense of deprivation tend to be associated with the belief that one is ineffective... There is too much despair and not enough anger" (Shapiro 2003, 127-127).

Without a legitimate threat to the status quo, it appears unlikely that increased oversight of corporations, decreased corporate lobbying, campaign finance or tax 
reform are going to emerge. Some sort of drastic challenge will have to occur - and it will likely come from the losers in the "winner-take-all" economy, as the winners are not likely to give up their privilege quietly. Just as wealth begets wealth, power begets power - the economically disadvantaged are at an ever-increasing political disadvantage - this is what must be overcome in the end. In any event, it is clear that vast economic inequality is a threat to the principles of self-government and equality of opportunity inherent in the American tradition, and the construction of a political theory that will adequately address it is the paramount concern of this paper. 


\title{
Chapter 2
}

Development in Liberal Discourse Regarding the Relationship Between Economic Equality and Economic Liberty

\begin{abstract}
In Chapter 2 a history of development in liberal thought and attention to economic inequality is traced. Through this process it is suggested that infringing upon individual economic liberty to a certain extent for the purpose of maintaining some degree of economic equality is compatible with liberal ideals on the whole. This is important to the conclusion of this paper, because I argue that the remedies proposed are compatible with the values of liberal American society.
\end{abstract}

Introduction

In the realm of political theory, classical liberalism is readily identifiable by, among other things, its defense of two concepts: equality of persons and individual liberty. These notions were a radical departure from the presumptions intrinsic to the feudalistic political structures from which they emerged. This chapter illustrates that while early liberal thinkers posited equality as an ideal and presumed inherent equality of individuals in crafting their theories, their focus was predominantly on the importance of liberty. Unforeseen by early liberal thinkers was that an unfortunate byproduct of liberty is, while people may be equal in inherent human dignity, they are not equal in ability. Over time this creates a de facto caste system, because in addition to natural talent and ability, some are born with economic resources unavailable to others. These resources create an inequality of opportunity to develop one's talents and abilities, posing a dilemma for liberal political cultures and social justice theory. 
As liberalism emerged as the status quo in countries such as Great Britain, France and the United States this became increasingly visible to liberal theorists, and evolved to be a predominant problem evaluated by liberal thinkers after World War II, which had been the result of, among other things, the inability of liberal political cultures to effectively deal with the economic problems of the day - a necessary condition for fascism to take hold. It turns out that birth matters even in liberal cultures where, in theory, it should not. In the United States a caste system has evolved, though it is not recognized as such. The liberal American political culture continues to hold itself up as the example of a society in which all are equal in opportunity, because anyone can, in theory, overcome tremendous obstacles and become the next Rockefeller, President Obama, Bill Gates, and so forth.

In theory all are equal in the United States, but in practice, where forced equality threatens the economic liberty of some, liberty generally carries the day. This is despite the fact that as seen in the work of Isaiah Berlin and John Rawls, in particular, the economically disadvantaged, by definition, are denied basic liberties. But in American culture poverty is viewed as more of a personal problem (the result of poor choices and such) and the myth (which is also the reality for some) that one has an equal opportunity to overcome that situation tends to prevail. An awareness of this dichotomy - that to obtain economic equality requires an imposition on the liberty of some, while allowing for economic inequality imposes upon the liberty of others - is apparent in the later works of Rawls and Berlin, in a way it was largely unnoticed by John Stuart Mill and entirely unnoticed by Benjamin Constant. 
This chapter is aimed at evaluating the manner in which liberal discourse evolved to address this tension between two fundamental features of liberalism: liberty and equality. For the purpose of this paper it will be treated as a progressive movement from a primary focus on Liberty to a primary focus on equality in liberal political discourse. The works of Benjamin Constant, John Stuart Mill, Isaiah Berlin and John Rawls are all evaluated for their recognition of economic inequality, the degree to which they concerned themselves with it, and the differences in their treatment of it, including speculation about how the manners in which they were situated in history may have affected these views.

While Constant presumed inherent equality, economic inequality appeared to be a given for him, and he focused on individual liberty to pursue one's interests and engage in commercial activity. Mill, writing one-hundred years later, did notice economic inequality, but while he also valued equality, defined as inherent human dignity, his concern with economic inequality seemed largely to arise from a sense of morality and humanitarianism, which led him in several cases to advocate for the freedom of the oppressed, the working class being simply one among others, such as women and African slaves. Isaiah Berlin was the first of these thinkers to take issue with the fact that the economically disenfranchised do not have the liberty to direct their lives as they wish. But his writings are concerned far more with the defense and protection of individual liberty from oppressive regimes than with the problem of economic inequality. John Rawls, on the other hand, was perfectly situated in time and place to notice this inconsistency in liberal political cultures - in the twentieth century United States, of which he was a product, liberty from an 
oppressive government was not a pressing political problem, as such, he was free to notice the problem of economic inequality. In contemporary America, the problem of economic inequality is not just something to notice, but a pressing issue of our time.

Benjamin Constant's Defense of Liberty Above All Else

Working on an apparent assumption of equality of persons, Constant didn't concern himself with natural inequalities or inequalities of wealth and privilege. At the time of his writing, liberal political associations were perhaps too new for him to foresee the problems that would be created. Perhaps having been socialized in the late $18^{\text {th }}$, early $19^{\text {th }}$ century, he may have adhered to equality as an ideal, even while his theories are inherently elitist - he clearly advocated governance by those who had the knowledge and the time to govern, which means wealth, but doesn't seem troubled by the idea that some people will be wealthy enough to have access to the opportunity to hold office and even vote and some will not. Rather he seems to accept that as the given state of things and doesn't appear moved to find that fact unjust or intrinsically unequal (Constant 1988, 214-217). Heavily influenced by Adam Smith, Constant's writings reflect the belief that individuals freely pursuing their personal interests promoted the public good. In addition he was European, and even contemporary Europeans maintain their nominal aristocracies, leaving at least a slight comfort with notions of privilege by birth, whereas Americans tend to believe their mythos that everyone is born equal. The reality of economic disparity 
combined with this mythology allows the de facto caste system that has developed in the United States to perpetuate unexamined - as presumably everyone has the opportunity to be as wealthy as possible, if they are willing to work hard and make smart choices.

Constant's primary concern was simply that men had the liberty to pursue their economic goals - he viewed the key to happiness as independently going about one's goals and pursuits, free from interference (Constant 1988, 104). He viewed liberty as priceless, "because it gives soundness to our mind, strength to our character, elevation to our soul" (Constant 1988, 110). While liberal societies hadn't developed to the point that wealth inequality became a visible issue at the time Constant was writing, even he had a degree of awareness of the privilege it provided, he just didn't seem to find it troubling (Constant 1988, 118 \& 214). He did, however, make a brief comment on "excessive wealth," in which he states that "wealth is power," but the recognition of this problem for Constant seems to be limited to the wealth of government accumulated through excessive taxation of the poor, as opposed to the contemporary problem of the excessive wealth of individuals, and the unfair competition for social goods as well as the imbalance of political power that situation creates (Constant 1988, 271-272). Constant's view was that the accordance of liberty to live their private lives as they deemed fit promotes an "intellectual equality" which he viewed as desirable (Constant 1988, 327). Writing amidst the turmoil of the times in which he was situated, freedom from governmental imposition and leaving individuals free to pursue their interests was the main focus for Constant. 
John Stuart Mill's Elitist Humanitarian Liberalism

John Stuart Mill made a significant contribution to political theory and his ideas evolved over time from an initial primary concern with liberty to reflect more recognition of the problems intrinsic to economic inequality. In On Liberty, as the title might indicate, he is primarily concerned with liberty, both from oppressive government and majority tyranny, whether state-sanctioned or not. He seems to presume economic inequality, but does not necessarily view wealth (or lack of wealth) to be an important factor in the exercise of individual liberty (Mill 2010, 8 \& 47). Like Constant, he presumed inequality of wealth and also presumed that the wealthy and learned are better suited to govern (Mill 2010, 43 \& 158). In his essay, On Representative Government, he does make references to the problems of the dominant class making decisions in its own interest, leaving the others powerless, but he does not seem to attribute this to a problem of wealth disparity, so much as the truism that "power" necessarily corrupts and that a proper government should have safeguards against abuse of power (Mill 2010, 161-165).

Where the principle of equality appears to enter the equation for Mill, just as with Constant, is a recognition that the wealthy, the state, the "natural aristocracy" or whomever, is not entitled to violate any individual's right to liberty. Moreover, he doesn't appear to be very egalitarian at all, except that he seems to presume equal political rights. Further, in some of Mill's work he appears to endorse a system of trade that inevitably creates and perpetuates economic disparity, stating the losers 
in the competitive game of trade are just that and it is not the business of the state to regulate (Mill 2010, 61). To be fair to Mill, it would appear from the development and revisions of his work in his lifetime that his opinion on this changed substantially over time, as he offered some positive analyses of communism, socialism and other types of cooperative and collective economic organization (Mill 1848, II.1.15). Mill seems to have noticed that pursuit of the private good doesn't always serve the public good the way that Adam Smith had predicted it would.

However economically progressive he may have been, however, Mill's elitism was evident. Like Constant, he presumes class distinction and doesn't appear troubled by it in and of itself. Most alarming is his willingness to restrict the liberty of those lacking wealth to procreate, without any seeming concern for this inequality infringing upon their liberty (Mill 2010, 69 and Mill 1848, II.12.9 \& II.13.4). He even posits that the solution to low wages is that the poor stop reproducing so much (Mill 1848, II.13.10). On the other hand he does seem to have some sense of a commitment to the promotion of equal opportunity to compete in society in his discussion of education, in which he supposes the state ought to pay for poor children to be educated if need be (Mill 2010, 67-68). Mill exhibits sympathy toward the idea that in a competitive laboring society - which he views as good - reforms were needed to benefit all by essentially ensuring a fair competition:

"And there is reason to rejoice at whatever makes the privileged classes of skilled artisans feel that they have the same interests, and depend for their remuneration on the same general causes, and must resort for the improvement of their condition to the same remedies, as 
the less fortunately circumstanced and comparatively helpless multitude" (Mill 1848, IV.7.65).

In his essay On Representative Government, Mill acknowledges a power differential between the "working-class" and the "masters." He argues that it is unfortunate that the workers have no voice in parliament, and that it is a problem, and he also explores the "evil" of low wages, but stops short of questioning the problem of the class distinction itself (Mill 2010, 136 and Mill 1848, II.11-II.13.1). He does briefly lament the "evil" of a "non-labouring class," but his concern that there exists a class which doesn't have to use its labor to contribute to the wellbeing of the whole of society doesn't seem to mean that he necessarily opposes disparity of wealth distribution (Mill 1848, IV.7.1-IV.7.2). Mill differs from Constant in that his ideal ruling class is not decided by property or any specific measure of wealth, but by intellectual ability (Mill 2010,158). So in terms of equality of offices and opportunity, wealth in itself doesn't seem to be a necessary factor for Mill, theoretically speaking, though in practice in the United States today, and certainly in the Europe in which Mill was writing, lack of wealth can be prohibitive in the ability of one to develop intellectual abilities to Mill's standard.

Mill's concern for equality is apparent in some of his writing such as when he discusses the problems of paternalism, including societal ideas about the alleged care and protection exercised by husbands over wives and the rich over the poor (Mill 1848, IV.7.4-IV.7.8). There appears to be an implicit qualification in his assessment in that he doesn't necessarily seem to see a problem always and everywhere of paternalism, but that the people who had hitherto been subject to it 
have now evolved and bettered themselves to a point that it is no longer necessary or even workable. Which seems to be rendering them more "equal," but it is a curious definition of "equal" as compared to that of Rousseau or Locke. This notion of the worker bettering himself is perfectly consistent, however, with Mill's commitment to and interpretation of utilitarianism. J.S. Mill's utilitarianism seeks the overall greatest happiness, but does not define happiness as pursuit of pleasure or wealth but as pursuit of "mental cultivation" (Mill 2010, 79-82).

In apparent contradiction to his defense of liberty, he also defends the possibility of enforced equality for the purpose of freeing a society from the "iniquities of a state of much inequality of wealth" (Mill 1848, II.1.7-II.1.8). In defense of communism, Mill speculates that because its aim is equality, any unjust situations that might arise in the application of it would be minuscule in comparison with the injustice and inequality in the economic system in existence at the time he was writing (Mill 1848, II.1.15). JS Mill's intellectual elitism is visible in all of the essays examined here, but he also defends a distributive method in a socialist system that does not compensate workers based on amount accomplished because some will be stronger or faster or what have you, and those workers who have already been given more by nature should not also be given more by society (Mill 1848, II.1.19).

Mill's work can seem less evolutionary and more incoherent on first glance. Because he never presented a comprehensive political theory, his essays on individual topics can seem contradictory. But in looking at the essays On Liberty, On Representative Government and The Principles of Political Economy more closely, it 
seems possible that J.S. Mill wasn't so much confused as he was focused on the topic at hand. So that one work doesn't necessarily contradict the other if we consider the possibility that his purpose in On Liberty was simply to defend liberty, not to examine the natural problems that arise from the practical application of say, The Harm Principle. It's possible that he might say his "socialist" views complement his "libertarian" views by introducing some of the principles that mitigate the problematic effects of individual liberty (Mill 1848, 9). Alternatively, he might say that a cooperative method of production and distribution, including collective ownership of the means of production (assuming here the liberal view of the state as representing and carrying out the people's will), should not necessarily infringe upon anyone's individual liberty (Mill 2010,135). This concept is fitting to Mill in a way it's not for Constant and most other early liberal thinkers, as freedom from tyranny is implied in the liberal notion of liberty, but beyond that, for Mill it is most importantly defined as intellectual freedom, whereas for Constant (echoing Locke) it was principally understood as freedom to pursue individual wealth. It does fit well with John Rawls' conception of civil society as a "fair system of social cooperation," though Rawls neither promoted nor prohibited any particular economic system - he seems to presume capitalism or some derivative thereof (Rawls 2001, 61 \& 71). Ultimately for Mill, while he is more concerned with the problem of equality than Constant, anytime he concedes some bit of sacrifice of liberty for its sake, he seems to view that as perhaps necessary, but not ideal. 
Isaiah Berlin Sees Economic Inequality as Problematic for Liberty

Like Constant and Mill, Isaiah Berlin focused a great deal of his work on the concept of liberty - with particular concern for freedom from oppressive governments. Berlin, however, was situated in a time in which liberal political associations had long become the status quo and subsequently failed in some ways to meet the needs of the population, opening the door for the rise of fascism and communism and their attendant assault on the concepts of liberty and equality (Berlin 2002, 69 \& 77). He had the perspective Constant lacked in that he could see the unintentional inequality that is the natural outcome of unrestricted individual liberty (Berlin 2002, 65). Further, it had come to be the reality that Constant had not considered, that as Berlin remarked, "political liberty is useless without the economic strength to use it" (Berlin 2002, 80).

While most concerned with liberty, Berlin does grapple with the issue that the realization of the liberal ideal of individual rights can (and does) yield economic injustice (Berlin 2002, 85). Berlin did not embrace socialism, perhaps in part due to his aversion to bureaucracies which are necessary to administer a socialist economic system or perhaps due to its tendency to be conflated with Communism, which Berlin viewed as oppressive, but most likely it was his concern for the impact socialism may have on individual liberty (Berlin 2002, 85 \& 228). Berlin also recognized the inherent goodness in a desire to protect equality, but sounding like John Stuart Mill, simultaneously lamented the bureaucratic state's infringement upon liberty to accomplish that (Berlin 2002, 91). He was concerned with a 
minimum standard of welfare - which should not be confused with equality - but remained devoted to freedom to pursue one's interests above all else (Berlin 2002, $92 \& 93)$.

In light of his concern for totalitarianism, it follows that liberty might be Berlin's overriding concern. Still, it is interesting to note that while Berlin does concern himself somewhat with economic inequality, and he does lament the rise of fascism - he doesn't seem to consider a possible connection between the economic discontent of the masses and Hitler's successful pursuit of oppressive power. He seems rather to view economic inequality as problematic only because it limits the choices and opportunities of individuals, not as a greater social ill that might help create the conditions under which despotism might flourish. On the other hand, Berlin appreciated the welfare capitalism that emerged in the United States as the result of the New Deal, praising it as a "great liberal compromise... between individual liberty and economic security" (Berlin 2002, 84).

Berlin is all over the proverbial map in some ways, even seeming to espouse multiculturalism when he addressed equality apart from equality of liberty and legal rights - in his discussion on paternalism, he addresses equality as a fundamental recognition of individual and minority group autonomy and ability to direct their own lives - not just merely leaving them alone to live as they wish, but respecting, not just their legal rights but their unique ability as well (Berlin 2002, 201-202). 
John Rawls' Construction of a Liberal Egalitarian Societal Structure

Of the philosophers considered in this section, the work of John Rawls embodies a clear and definitive shift toward which Berlin seemed sympathetic, but not necessarily committed to, and that is the indispensability of equality in liberal society, even if it means inhibiting the personal liberty of some. In deference to liberty, Rawls' theory allows for economic inequality, but only if the least well off better their position, and does not allow for political inequality or inequality of opportunity (Rawls 2001, 42-43). As being evaluated by its commitment to equality, the theory is sound, but unfortunately, in practice as illustrated previously in this paper, where there is economic inequality, political inequality and inequality of opportunity tends to follow.

John Rawls was strongly influenced by Kantian egalitarianism and constructed his theory of justice "within the framework of a Kantian social contract theory" (Rawls 2005, 265). It's not enough, however, for the purpose of this paper to suggest that Rawls held equality to be an indispensible political value - as liberal thought is defined as such - all of the liberals considered in this paper, hold equality, defined as equality of the inherent human dignity of persons, as a matter of importance. The interesting shift, explored and noted somewhat by Mill and Berlin, becomes very clear in the work of John Rawls. This is the unequivocal recognition that equality is more than simply a statement about equality. If people are indeed equal in dignity, the circumstances into which they are born, should not, in effect, 
render them unequal in terms of opportunity and ability to participate in government or pursue their particular interests (Rawls 2001, 55 \& 124).

Rawls, like Berlin, worried about the effect of economic inequality on political equality. Whereas Berlin praised the welfare capitalist state that the United States had become, Rawls recognized that a commitment to a minimum standard of welfare for all citizens satisfied the concept of giving to all what they deserve by "virtue of their humanity," but that it falls short of what they deserve as "free and equal citizens" (Rawls 2001, 129). He conceived of distributive justice as a system that fairly regulates distribution over time so that all citizens perceive themselves as free and equal members of society with equal opportunity regardless of their natural abilities and so-called "good luck" or lack thereof (Rawls 2001, 130).

Rawls argued that economic inequality can seem unfair in itself when some have too much while others have too little, but the real problem is that it leaves the less advantaged susceptible to domination by the more advantaged (Rawls 2001, 130-131). He was concerned with not just the fairness of an individual transaction, as interests the libertarians, but with the fairness over time. He recognized that due to changing circumstances, the accumulation of any number of fair trades and agreements over time can inadvertently erode the initial condition of "free and fair." To deal with this Rawls emphasizes the importance of the basic structure's ability to maintain "background justice" (Rawls 2005, 264-267). Because fairness is naturally eroded over time, even through fair transactions, Rawls suggests special institutions are necessary to regulate this over time - he does not favor a system of overgoverning individual transactions, however. Rather, he presumes a basic structure 
of society that will take care of these things, leaving people more free to pursue their interests within that framework (Rawls 2005, 267-269).

Rawls' two principles of justice illustrate a commitment to fairness, egalitarianism and liberty, but in Rawls' theory economic liberty does not trump economic equality, in fact one could argue that liberty is simultaneously subordinate to and protected by equality. The first principle of justice requires that each person enjoy equal basic liberties. The second principle, as stated above, allows for social and economic inequality if there is equality of opportunity to occupy offices and positions and if the least advantaged benefit from the generated wealth (Rawls 2005, 291). Rawls is concerned with specific liberties but not all, it seems, as he clarifies: "No priority is assigned to liberty as such, as if the exercise of something called 'liberty' has a preeminent value and is the main if not the sole end of political and social justice" (Rawls 2005, 291-292). Because he is unwilling to assign unqualified importance to the open-ended term "liberty" he is in a good position to assert that economic liberty needn't operate unrestrained (Rawls 2005, 292). He further sets himself up in this direction by making a distinction between "restriction" and "regulation" of basic liberties (Rawls 2005, 295). Rawls doesn't use that phraseology to discuss economic pursuits, but the concept could have rather smoothly made that transition. When addressing specifically the issue of distributive justice, however, rather than taking it on as something in and of itself, Rawls assumes that if his basic structure is in place, then distributive justice is defined as a "pure background procedural justice" (Rawls 2001, 50). Individuals may act as they wish within the framework and the institutions regulating to ensure 
the distribution of goods is fair and equitable (Rawls 2001, 50). Furthermore the background institutions are to function in a manner that keeps the inequality of wealth accumulation allowed by the difference principle from becoming too vast, thereby jeopardizing equality of opportunity. Inheritance laws and taxes are examples of the procedures put in place to regulate this over time (Rawls 2001,51).

According to Rawls' theory the way to determine if the least well off are benefitting from an inequality is by following the maximin rule in the initial setting up of the basic structure. Looking at the maximin rule is an exercise done in the Original Position, not something that is an ongoing function in a society - it is used for the purpose of setting up the structure (Rawls 2001, 97-99). What is unfortunately unaddressed by Rawls is that in choosing the option that has the "best worst outcome" it is unclear what position the least well off are left in. It wouldn't compute with the rest of Rawls' argument if he presumed it just for the least well off to continue to be destitute while others became excessively wealthy, but nor does he address any sort of minimum standard in a very helpful way. He does suggest a minimum standard that might be accomplished through income transfers, but the minimum standard is defined as "the long-term prospects of the least favored extending over future generations" (Rawls 1971, 284-285). As was shown in the first chapter, even when the bottom quintile achieve some percentage of income growth, the ratio of what they have gained compared to what the top quintile has achieved can be so great as to threaten other important elements of Rawls' social justice theory. Rawls' first principle of justice along with the principle of fair opportunity and the savings principle (which is designed to preserve equality of 
opportunity through generations) all constrain the difference principle. However, these are all based on a premise that a minimum standard satisfies the goals of social justice, which this paper does not accept.

He addresses the notion of minimum standards when advocating for a property-owning democracy as opposed to welfare capitalism - suggesting that welfare capitalism provides what is minimally required for the purpose of human dignity and that a property-owning democracy offers the minimum of what is owed to free and equal citizens in a socially cooperative situation - and hopes that by following the two principles a consistent "underclass" of disadvantaged people uninspired to participate in the political process would not develop. His problem with it is the recognition that meeting minimum standards does not promote equality (Rawls 2001, 129-131, 138-140). One example that illustrates this dilemma is in 1984 when Ronald Reagan invited voters to re-elect him if they felt they were better off than they'd been 4 years prior. Just because average Americans felt better off than they'd been during the stagflation of the 1970s, does not mean that the policies enacted that facilitated a redistribution of income growth and wealth accumulation to the very few at the top of the wealth scale was a sound policy worthy of continued endorsement (Shapiro 2003, 117).

Rawls does address inequality in terms of moral desert. He posits that no one deserves any good (or bad) fortune obtained by virtue of birth. And he wants to replace the moral desert framework of distributive justice with a concept of legitimate expectations and entitlements. He presumes that doing so must somehow address what he calls the "most serious of inequalities" which is that of 
"prospects" and argues that inequalities of prospects are most likely to be related to the level of wealth into which one is born (Rawls 2001,77). If prospects are largely determined by the level of wealth into which one is born then the policy of inheritance should be troubling to Rawls, but he considers it permissible "provided that the resulting inequalities are to the advantage of the least fortunate and compatible with liberty and fair equality of opportunity' (Rawls 1971,278). One can only guess how the advantaged (those with enhanced prospects due to being born into wealth) having the ability to inherit wealth could possibly benefit the already least advantaged who will never inherit anything. Rawls attempts to remedy this by advocating for a progressive inheritance tax, which he might argue is then put in the public pool to fund programs that support the least advantaged, but it's difficult to argue that this system leaves the least advantaged better off than if the entire amount was not inheritable to one or a few individuals, even after being taxed (Rawls 1971, 279). If justice is fairness, there are few phenomena less "fair" than wealth by inheritance. And Rawls acknowledges that when inequalities of wealth become too great, equality of opportunity is threatened, but his reliance on taxation to keep this gap from becoming too great is problematic because as stated above, inheritance, in and of itself, does not meet the criteria of the difference principle (Rawls 1971, 278). 
Post-Rawls Liberals and the Pressing Concern of Economic Inequality

Economic inequality and the problems it poses for the core values of liberalism have increasingly been the focus of liberal thought. Several contemporary liberals have specifically built upon the work of John Rawls. Brian Barry, for instance, specifically used Rawls' basic structure in his work examining economic inequality and injustice, attempting to address the problem Rawls' maximin principle poses for economic equality over time. While Will Kymlicka largely addresses the issues posed by communitarians and multiculturalists, he also acknowledges economic discussions within liberalism. Kymlicka expresses a concern for marginalized groups by questioning the traditional liberal acceptance of welfare capitalism - including the fundamental injustice of reliance upon a growth economy, which the difference principle also does - and points out that Rawls' difference principle might best work under a market socialism system (Kymlicka 1989, 90-91). This would address the concern posed above in that when choosing the "best worst outcome" a minimal standard of material goods would be presumed. Rawls had found welfare capitalism problematic as well, stating that it did not "realize all the main political values expressed by the two principles of justice" (Rawls 2001, 135). Kymlicka also holds up John Stuart Mill's comfort with socialism as evidence that socialism is perfectly compatible with liberalism. Further he points to Dworkin's auction scheme as perhaps a more egalitarian system (Kymlicka 1989, 91). His egalitarian concern in this discussion is not based on class issues so much as gender inequality, which he, unlike liberals in years past, recognizes to have a 
strong economic component. He posits that to state women are autonomous beings is well and good, but without economic resources they are not free to direct their lives independently (Kymlicka 1989, 89-93). In all cases he concludes that some sort of economic equalizing system is a necessary concern for liberalism. While he defends Rawls and Dworkin, he also calls them to task for not addressing the "entrenched inequalities of class and gender," presuming their theories don't endorse this condition, and wondering why they failed to question it (Kymlicka 1989, 111).

The Ethics Based Approach of Ronald Dworkin

Ronald Dworkin argues that with regard to equality, "dignity requires equal concern for the fate of all and full respect for personal responsibility" (Dworkin 2011,338). He pictures liberty and equality not just as compatible values, but as intertwined (Dworkin 2011,331). Putting aside Dworkin's curious premise that the reason left-of-center politicians struggle to obtain incremental gains for those at the bottom of the economic scale is because politicians can't ask for more than "the majority are willing to give," it is useful to consider his analysis of equality and economic policies that appear to exist for the sake of liberty4 (Dworkin 2011, 351). He begins by positing there is value in "troubling the comfortable" with the issue of poverty, because in the present time "their selfishness impairs the legitimacy of the

\footnotetext{
${ }^{4} \mathrm{His}$ argument is ambiguous on this count and therefore can't be analyzed very effectively, but clearly the majority of people are not at the top of the economic scale. Even as this statement of his doesn't appear to be factual unless his meaning is simply unclear, the argument that proceeds from it is sound.
} 
politics that makes them comfortable," and we must not also let them think they are justified in their positions (Dworkin 2011,351). He argues that those in a political community should be equal in material resources as a start, because without that individuals do not have the liberty to pursue what makes them happy. He acknowledges that some people may choose to pursue poetry rather than something that commands a higher price in the market and therefore exact economic equality is undesirable at best (Dworkin 2011, 355). Dworkin's focus on liberty is that individual liberty is a necessary component of treating citizens with equal concern and further that liberty and equality are mutually affirming, "not independent virtues but aspects of the same ideal of political association," (Dworkin 2000, 181182).

\section{Conclusion}

In the United States, of which Rawls was a product - if not everywhere - the problem of economic inequality cannot be divorced from political inequality and inequality of opportunity. Constant hadn't seen the problems posed by economic inequality, assuming that liberty would leave people free to pursue their private interests, leaving everyone better off. Mill seemed to be concerned with this point, but more as a moralist and humanitarian. Berlin's primary concern regarding equality was the manner in which lack of economic resources acts, in effect, to restrict the liberty of individuals to direct their own lives. Rawls, in contrast to all, views equality of opportunity - and if not equality in distribution of resources, at 
least equality of protections under the institutions that govern the distribution of resources - as important in and of themselves. Perhaps as an American living in the middle and late part of the twentieth century, he simply took liberty for granted in a way the other three were not able to do, and so was inclined to not be unconcerned about it, but to not see it as the most pressing political problem of his time and place.

At liberalism's inception, it could not have been known how precarious the balance between liberty and equality would become or how various economic systems might promote one over the other. The injustice that economic inequality inhibits the individual liberty of some to direct their own lives combined with the quandary that the prevention of economic inequality inhibits the individual liberty of others to pursue their economic interests is a critical contemporary problem that liberal political theory may not be equipped to reconcile and may require at least some elements of a more communitarian approach that recognizes the interdependency of humans - such as that proposed by Michael Walzer, which will be explored in the following chapter. 


\section{Chapter 3}

That political equality and equality of opportunity is necessary for a just society is undisputed

In Chapter 3 the views of contemporary theorist from liberal, communitarian and to a small extent multiculturalist camps are examined with regard to the importance placed on economic equality. First we establish that all of the social justice theories considered for this paper agree that economic inequality matters insofar at it affects political equality and equality of opportunity. Then the various ways theorists deal with balancing or constraining economic inequality is examined. These are then built upon for the final chapter of this paper in which constraints, conditions and methods for correcting economic injustice are explored.

\section{Introduction}

The purpose of this chapter will be to examine the issue of economic inequality insofar as it poses a problem for the concept of social justice in a pluralistic society. The exploration presumes that mechanisms designed to promote social justice are, and/or should be, intrinsic to the structures and institutions governing civil society.

Relying upon John Rawls and theorists who have built upon or reacted against his work, this chapter is directed at evaluating the assumption inherent in these theories that vast inequalities of wealth can exist in a just society. Rawls allows for this if his "difference principle" is satisfied, Michael Walzer allows for this as long as basic human needs are met, Robert Nozick allows for this if the wealth was obtained legally, while Iris Marion Young asserts that the issue is not the overriding problem for the achievement of a just society in any event. 
Relying heavily upon the work of Brian Barry and Ronald Dworkin, this chapter will attempt to illustrate that, whether or not money ought to be able to purchase political power and opportunity, it does do so. And looking back to the original contract theorist, Rousseau will illuminate the injustice of economic disparity in a contract-based society. In conclusion it aims to propose that a theory of justice must address this fundamental social phenomenon if it is to be politically useful.

John Rawls' Liberal Theory of Justice

John Rawls' theory of justice reflects a classical liberal approach with regard for autonomy, liberty and equality being upheld as the highest values. His theory is contract based and presumes that the purpose of establishing a system of justice is to ensure that the responsibilities and goods necessary and available to a social group are fairly distributed (Rawls 2001, 7.). The difference principle arises from Rawls' commitment to egalitarianism, allowing for disparate accumulations of wealth but only if the accumulation occurs on a level playing field where no one was arbitrarily advantaged via natural talent, birthright, etcetera (Sandel 2009, 156).

Rawls' Two Principles of Justice first set up the basic structure of society which ensures basic political equality and liberty for all but allows for economic inequality so long as equality of opportunity governs the ability of all to hold offices and positions, and so long as the least well off members of society benefit from any inequality of wealth generated. The latter part is known as the difference principle, 
Rawls' primary answer to the problems posited by the vast inequalities of wealth that appear to occur in such a system (Rawls 2001, 42-43).

Rawls is sensitive to the limitations on the problems the difference principle is able (or not able) to address. His answer to that is that the difference principle can only be applied after the first two principles of equal liberties and equal opportunity are firmly in place (Rawls 2001,43). As a theory in the mythical original position, which Rawls constructs, this could be an adequate explanation. However, if the goal is to ensure social justice in civil society, Rawls must answer to the fact that economic inequality creates, legitimates and perpetuates political inequality and inequality of opportunity - if not in all civil societies, certainly in capitalist, welfare capitalist and property-owning democratic societies (Rawls 2001, 135-136). Even if all are eligible to hold offices and positions of power, where vast economic disparity exists humans are placed in an unequal bargaining position when competing for and/or negotiating participation in them - Rousseau's Social Contract, which Rawls builds upon, as well as his Discourse on Political Economy both anticipate this quandary for social justice theory.

As Rousseau illustrates the person in possession of vast wealth commands a privilege in society that a poor person does not. And further the wealthy person has advantages offered him by cooperating in civil society that are not known to the poor person (Rousseau 1913, 160-161). Rousseau asks, "Are not all the advantages of society for the rich and powerful?" and laments that "all this respect costs him nothing," in contrast to the poor who, "if ever he obtains justice, it is with much greater difficulty than others obtain favors" (Rousseau 1913, 160-161). Following 
this it is difficult to defend a theory of social justice that doesn't account for the ease with which the wealthy continue to get wealthier and the continual struggle that it is for everyone else to survive. It is not new that "nothing comes out of nothing" - that it is more difficult to accumulate money starting from zero than it is starting from even a modest fortune (Rousseau 1913, 162). This truism is readily recognized in pop culture as well. During a 1978 Saturday Night Live monologue Steve Martin joked that he knew how to become a millionaire and avoid paying taxes, "First get a million dollars..."

Rawls does propose that if the basic political structure is functioning then specific issues of distributive justice should be able to be decided fairly by the institutions already in place, such as courts (Rawls 2001, 49). For Rawls distributive justice assumes social reciprocity in that resources are not just allocated but that they are in a sense earned through social cooperation (Rawls 2001, 51). But how does one obtain a position on said courts and what of the issue of unequal bargaining positions? In a capitalist system the rich need the labor of the poor every bit as much as the poor need the money offered by the rich in exchange for labor, but the reward of the work done by each is nowhere near equal. This is problematic for Rousseau who suggests that the point of giving up certain freedoms to live cooperatively is because everyone benefits from the cooperation of the rest (Rousseau 1913, 195). According to Rousseau natural law suggests everyone has a right to everything he needs and no right to occupy more land than he needs for himself - he further claims that one can only maintain a sizeable amount of property by force because "all others are being robbed" of their habitat "which nature gave 
them in common" (Rousseau 1913,197). Rawls' commitment to equality in the original position is a good start, but as Rousseau points out, given that inequality of strength and intelligence exists in nature, any justice theory that relies on social contract theory will insist on laws that enforce equality by legal right. As laws generally are designed to protect those that have something to lose from those who do not, Rousseau also suggests that civil association is only advantageous "when all have something and none too much" (Rousseau 1913, 199).

According to Rousseau there is a universal justice that emanates from God as well as from reason alone, but a just outcome depends upon mutual observance and only the just will observe those natural rights, leaving the "wicked" to benefit. Because of this, laws are needed to "join rights to duties" (Rousseau 1913, 210). Among those laws Rousseau suggests is that the existence of both very rich and very poor people are detrimental to the common good. He doesn't appear to view this as so much a problem for justice, but as a threat to liberty and stability, as he points out that when some men are rich enough to buy others and others so poor they have to sell themselves, the door is opened to tyranny and otherwise destruction of the state (Rousseau 1913, 225-127).

Rawls sets out the notion of a property-owning democracy as a way of structuring society that would prevent vast inequalities of wealth accumulation because it would distribute ownership of the means of production in a more equal fashion and proposes it implies a constitutional democracy that will protect the liberties and equality of opportunity without regard to possession of wealth (Rawls $2001,145)$. The problem again is that while constitutional governments may in 
theory protect all citizens, those who can purchase rights, opportunities and power are still able to do so over those who cannot, a sound theory has to recognize this. There doesn't appear to be a good answer to this in Rawls' theory, though he does suggest that the basic structure and a property-owning democracy would by definition have procedures in place that would keep the distributions of wealth from becoming extremely disparate through functions like inheritance laws and taxes (Rawls 2001, 51). Still the fundamental problem with the difference principle remains - that is, if one person is permitted to accumulate unlimited wealth with the only caveat that the least well off becomes even just slightly better off, the door has opened for grossly uneven distributions of material wealth.

The idea behind the difference principle is it should not establish more attractive prospects for the already advantaged unless doing so also advantages the least well off, and social cooperation should be mutually advantageous (Rawls 1971, 75 \& 77). However, Rawls accepts as a given that there will be social classes and some will start out with better prospects than others and states this is just if "the difference in expectation is to the advantage of the representative man who is worse off..." suggesting that in some cases lowering the expectation of the more advantaged may also be detrimental to the lesser advantaged (Rawls 1971, 78). Just as with "trickle down economics" Rawls suggests that the entrepreneurial class provides opportunities and such for the laboring class, thereby allowing their privilege to benefit the less privileged, and that something along these lines must be true in order to justify these inequalities (Rawls 1971, 78). This is confusing in light of his commitment to open offices and institutions. What good is it that offices are 
open to all, if only some are afforded the opportunity to acquire the skills and education necessary to be hired or elected to them?

In light of the current state of dramatic income inequality and the limitations that has placed on equality of opportunity, Rawls' defense of the difference principle offers a caveat:

"How unjust an arrangement is depends on how excessive the higher expectations are and to what extent they depend upon the violation of the other principles of justice, for example, fair equality of opportunity;" (Rawls 1971, 79)

In this statement Rawls concedes that excessive inequality produced under the constraints of the difference principle can produce conditions in which his basic principles of justice are violated. He goes on to acknowledge that the larger the difference between rich and poor the more likely the poor are left worse off, thus violating the principles of mutual advantage and democratic equality (Rawls 1971, 79). So in that instance the requirements of the difference principle are not met, but even when the requirements are met, initial inequality is still a given:

“...each man's position is improved with respect to the initial arrangement of equality. But it is clear that nothing depends upon being able to identify this initial arrangement; indeed, how well off men are in this situation plays no essential role in applying the difference principle" (Rawls 1971, 80).

So the requirements of the application of the difference principle in any particular instance should constrain a tremendous inequality of gain by each party in that instance, but it does not address or constrain cumulative inequality over time. Furthermore it ignores the caveat of Rousseau that relative equality matters that differentials in economic standards can allow some (or one) to exert excessive 
power over another (or many). An example in which the difference principle is satisfied, but the conditions produced are objectively unjust is sweatshops - the theory behind the good of sweatshops is in keeping with Rawls' idea that "within just social arrangements something like a general diffusion of gains does take place, at least in the longer run" (Rawls 1971, 82).

A modern day global example of this problem is the way in which American corporations exploit the labor pool in the developing world. The extremely wealthy corporations attempt to justify the low wages and inhumane working conditions they benefit from by suggesting that the employees are at least better off financially than they had been without jobs. Historically, economically and empirically this may be an accurate statement, but it doesn't follow that this is enough to satisfy the principles required for social justice (Rivoli 2005, 105-119). When group A controls resources that are necessary for the survival of group B, and can therefore threaten the group B's basic interests, the balance of power relations is upset according to Ian Shapiro's definition of domination (Shapiro 2003,4). Those who are in a desperate situation are not in an adequate bargaining position and therefore do not receive the true value of their labor. This is a problem even for libertarian theorist Robert Nozick, whose theory of distributive justice will be critiqued more thoroughly in a later section.

In a contract-based society where people are left free to pursue their economic interests via entering into freely negotiated agreements, vast inequality of wealth is a problem. According to Nozick - "equal rights" includes the liberty to enter into contracts, and therefore whatever economic result appears is deemed to 
be fair. But contractual relationships are not necessarily contracts negotiated among equals - this is particularly true when there is an inequality of economic need. If one party is in desperate need of the negotiated item and the other party is not, there is not effectively a negotiation going on. More than several historical dramas illustrate this fact, among them the case of Lochner v New York in which Lochner, a bakery owner, challenged a law mandating employees not be allowed to work more than 60 hours per week on the grounds that it interfered with his right to contract. Not surprisingly Lochner was able to find an abundance of employees willing to work more than 10 hours in a day if that's what they needed to do to have a job, whether that comported with the best interest of their health and safety or not. They were not in a position to negotiate their work hours at all. Furthermore, if "taxation of earnings from labor is on par with forced labor" as Nozick asserts, how does the entering into contractual relationship among non-equals not equate to forced labor? (Nozick 1974, 169). The collection of taxes is an important point for the purpose of contract negotiations among people in unequal bargaining positions. Tax money is used, theoretically and in part, to maintain various things that contribute to the common good - among them, labor laws that protect those who are in an unequal wage-bargaining position.

Michael Walzer's Communitarian Response to Rawls In contrast to Rawls' traditional liberal account of social justice principles, Michael Walzer bases his idea of social justice on a communitarian notion of 
"complex equality" in which wealth is simply one social good among many and its value is dependent upon the relationship of those members of a given community. In his vision of a just society, having a great amount of wealth does not translate into the ability to purchase other social goods such as political power, educational opportunity and the like (Walzer 1983, 10).

In Walzer's assessment politics is the route taken to power, which then allows one person or group to dominate some social good or other (Walzer 1983, 15). Of course this can also work in the reverse - that the possessor of excess wealth can buy political power. Walzer acknowledges in many places that money should not operate "outside its sphere" such as when he remarks on a story about George Orwell's school experience that it is a "perfect illustration of the tyranny of wealth and class over learning" (Walzer 1983, 212). He is well aware that money oversteps the sphere in which he would like it to stay, but stops short of suggesting that artificially equalizing wealth at least to a certain degree might be a necessary ingredient for a social justice theory (Walzer 1983, 12).

Walzer creates a list of the things money can't buy, not asserting that it doesn't buy those things but that if (and when) it does, it is an unjust transaction (Walzer 1983, 100-103). And while his list is thorough and accurate, money does unfortunately buy many of the things on it - this is the fact that is most troubling and important in the development of a social justice theory. Walzer might counter that all we owe to each other as citizens is what basic human dignity requires (ie the necessities), but while he didn't address the issue of whether excessively large wealth gaps may be unjust by definition, artificially regulating how large that gap 
should be allowed to be could still be compatible with his overall theory that money should only be able to rule within its sphere. Walzer asserts, "political power (rather than the means of production) is probably the most important, and certainly the most dangerous, good in human history" (Walzer 1983,15). But it seems clear that in the United States those who own the means of production are at a particular advantage in terms of political power, suggesting that the way to equalize political power is to equalize economic standing.

Walzer is sensitive to vastly unequal distributions of wealth but his only solution is to propose a form of welfare capitalism or socialism in which everyone in society has their basic needs met and from there, a "surplus" of wealth can be distributed however it happens (Walzer 1983, 75-76).

"Hungry men and women don't have to stage a performance, or pass an exam, or win an election" (Walzer 1983, 75).

His commitment to meeting the basic needs of fellow citizens is certainly more clear than that of Rawls, but it still fails to address that those who possess the surplus are not only going to be buying extra trinkets and doodads but also better education, better positions and greater political power - whether money "ought" to be able to purchase these types of goods or not (Walzer 1983, 22). And therefore we cannot conceptualize a theory of social justice without including some sort of wealth equalizing mechanism. Following Rousseau Walzer argues,

"Men and women who appropriate vast sums of money for themselves, while needs are still unmet, act like tyrants, dominating and distorting the distribution of security and welfare" (Walzer 1983, 76). 
As addressed previously, limiting people's ability to do this should not be viewed as an infringement on individual liberty as some, such as Nozick, want to suggest, precisely because wealth is only obtainable and meaningful within civil society, and there is nothing oppressive about recognizing that everyone's labor and consumption habits are necessary to perpetuating the market economy. Robert Nozick and the Libertarian Theory of Justice

For Robert Nozick, you rightly have what you rightly acquire or what someone has chosen to give you from his/her rightful acquisitions (Nozick 1974, 160). This is based upon John Locke's State of Nature theory in which all that you have put your labor into is rightfully yours and supposedly individuals have rights, even if they are not enforceable. This is the problem with state of nature theory - it may be well and good to suggest that there is some set of divine rights that people ought to have, but without a cooperative community that acknowledges those rights, people do not practically have any rights at all. Therefore to create a social justice theory that presumes one person's privilege doesn't to some degree depend upon the recognition of others in the community that that privilege is deserved, is to ignore the degree to which everyone's relative success is dependent upon the community in which they live.

Nozick argues that, "No distributional patterned principle of justice can be continuously realized without continuous interference with people's lives" (Nozick 1974, 163). This is a fair and accurate statement, but politics and political systems 
are by their nature an interference with people's lives. If politics is the way to address social problems, it necessarily follows that it will interfere in people's lives presumably for the good of all the people who are subject to it. Nozick is in favor of the state interfering in say a hungry person's attempt to meet his needs by "stealing" bread from someone who has managed to accumulate an excess of bread. But should the state intervene to suggest that the person who has accumulated too much bread is effectively "stealing" from those who need it and who are not any less deserving of it, this is an injustice, according to Nozick. History shows us that tremendous policing by the state is necessary to protect the wealthy few from the desperate masses - a state committed to social justice should likewise protect the masses from exploitation by the wealthy few. If a minimal state is justifiable to protect the physically weaker possessor of an object from a physically stronger person who is capable of taking it from him, then why is it not justifiable for the state to protect the dumb from being exploited, or tricked or simply outwitted by the smart or the disadvantaged by birth from the advantaged by birth?

For Nozick the ability to fairly and freely enter into contracts is of paramount importance, but his theory doesn't have an answer to a problematic truism of negotiation. If two people are negotiating a division of $\$ 100$, the person most in need of money will likely receive the least, because he will be most likely to settle for whatever he can get - if Nozick accepts as just a minimal state to protect the physically weak owner of a possession from the ability of a physically stronger person's ability to take it from him, then it doesn't follow that it is unjust for a state to protect the mentally or economically disadvantaged negotiator from the party in 
the strongest position. A Libertarian viewpoint does not have an answer for the implicit advantage some have in perpetuating and maintaining the status quo and by definition limiting the opportunities of those who begin less well off over time. Even if a libertarian would allow resources "legally obtained" to be horded by the few who are able to horde them simply because they are able - the artificial equalization of bargaining positions should not be a point of dispute.

Nozick makes a good point that wherever people have access to any resources, some will use those resources to acquire things they specifically want and others will squander all that they have - there is no apparent solution to this (Nozick 1974, 163). Therefore the solution must lie in the protection of equality of opportunity (both economic and political) for each new generation.

Redistribution of economic resources for Nozick is a violation of people's rights (Nozick 1974, 168). In discussing necessary constraints on the state, Nozick argues that it is absurd to suggest that some persons should have to pay a cost in the name of the overall social good. He goes on to claim that the person being forced to pay from what is (allegedly) rightfully his in order to benefit others in the community is "using" him - that "something is done to him for the sake of others" and that cloaking this event in the language of "social good" does not make it any more permissible (Nozick 1974,33). The problem with Nozick's argument is that it leaves out the entire discussion about who this individual "used" in order to accumulate enough that a society might think he should give some of it back for the common good. If, for example, this individual found ten hungry people who were willing to work for him at minimal wages, could we not say he "used" them? If the 
government guaranteed a loan so he could start a business, has he not "used" the people who support and make up that government? Nozick might say that he doesn't support the sort of government that exists in the United States today, in that it subsidizes corporations and guarantees loans and such, but even if we peel back the layers of that and attempt a bare bones government as Nozick suggests, it is not possible for an individual to accumulate excessive wealth without the help of anyone else - there are workers and investors, there are natural resources and land used in most cases, there is a government whose policies allow the use of those resources and protect the accumulated wealth, there is a social compact in place that agrees upon what is valuable and what is not. These sorts of cooperative agreements do not suggest that it is ok for the few who amass great wealth under this system to then use their collective power to enact governmental policies that diminish the economic opportunities available to others.

Michael Sandel's Communitarian Analysis of the Libertarian Theory of Justice Michael Sandel offers some insight into the problems surrounding the justness or lack thereof of inordinate inequalities of wealth through a thoughtful analysis of the libertarian view of justice and is critical, in particular, of that view as presented by Robert Nozick (Sandel 2009, 62-72). Sandel's communitarian approach offers a much more realistic portrait of why civil society develops and what people both gain and lose for the sake of being part of it than does Rawls' liberal view of civil society in which the individual precedes his social structure. 
For Robert Nozick individual rights reign supreme and the only just state is a minimal one functioning solely to protect those individual rights and enforce contracts (Sandel 2009, 62). The most glaring shortcoming of this view is that it ignores that "rights" do not precede the governments that uphold them and therefore there is implicit responsibility on the part of the individual to also support the state and the other members that make up society from which individuals benefit.

For Nozick vast inequalities of wealth are justified if the wealth was accumulated using one's own resources and via free market exchange - assuming those conditions are satisfied it is unjust to redistribute excessive resources (Sandel 2009,63 ). To think these conditions could exist (or at least that they routinely exist) is to ignore the ways in which vast wealth accumulates - generally through a corporation and/or government appropriating some physical resource and creating a condition in which the people living in the immediate vicinity of that physical resource can no longer sustain themselves without working for that corporation/government. The people in the immediate vicinity of this are then dependent on that entity for their survival. To pretend that those people are in a fair bargaining position with the holders of the income-producing asset is an injustice to those people. Furthermore the wealth accumulated by having the power, the knowledge and the means to orchestrate that condition ought not just benefit those few who were privileged enough to create the condition. They are no more entitled to a disproportionate sum of the fruits of the laborers they conquered than are the laborers themselves. 
Both Nozick and Sandel, however, muddy the issue by focusing on an individual's wealth attained by some highly valued skill in a society's time and place such as that of Wilt Chamberlin and Michael Jordan respectively (Sandel 2009, 6466). The issue is slightly more complex when viewed as such because one could make the case that Michael Jordan didn't harm anyone in earning his money, nor did he force anyone to purchase tickets to his basketball games and therefore his resources now belong to him alone. However, Michael Jordan didn't materialize in a vacuum; he has been able to achieve what he has achieved because of the political and economic structure of the country in which he lives, which is made up of a citizenry that has nurtured him along the way. Michael Jordan might not have grown up to be a basketball star if he'd been chained to a loom in Bangladesh from the time he was four years old, for instance. Nozick might reply that Michael Jordan is still rightfully entitled to his earnings based upon his view of cooperation.

In short, the Libertarian justification for allowing vast inequalities of wealth ultimately rests on a notion that people have a right to all that they accumulate by virtue of their own labor (Sandel 2009, 68-72). But there is no such thing as a "right" without either a government to enforce and uphold that right or a community that is in agreement with respecting that right or both. In theory one can embrace the notion of natural or God-given rights but in practice there has to be agreement about what that entails. The notion of rights implies relationship and as Iris Marion Young points out, "Rights are not fruitfully conceived as possessions" (Young1990, 25). Because of this rights imply a kind of reciprocity and a theory of social justice must address how the stronger, more talented, luckier and what have 
you benefit from the weaker, less talented, less lucky and so on. Even if this were deemed just, the vast inequalities of resource distribution subsequently set up an environment in which those lucky few are even better able to at best benefit from and at worst exploit those unlucky many.

Rawls is sensitive to this and asserts that justice requires social institutions such as taxes and inheritance laws to ensure that fundamental individual liberty and equality are not compromised over time by equaling out somewhat how much can be accumulated (Rawls 2001,161). Young also addresses this by pointing out that it's helpful to look at patterns of distribution over time, as simply looking at an instance of distribution does not offer enough information for determining its fairness - one also needs to analyze how the distribution came about - in other words, that the process of distribution is as important as the product (Young 1990, 29-30).

Iris Marion Young's Criticism of Traditional Distributive Justice Arguments and the Limitations of Identity Politics in the Articulation of Social Justice Theory

Not everyone agrees that distributive justice is the most fundamental and important factor for social justice. Iris Marion Young employs the critical theory tradition in criticizing the tendency to focus on distributive justice as missing the more important issue, which in her view is institutionalized prejudices - in other words the ways in which racism, sexism, homophobia, etcetera are intrinsic to and legitimated by the institutions of civil society (Young 1990, 15). "Domination and oppression," in her words, are an overlooked cause of social injustice and while she 
accepts that distribution of resources is important she rejects that it is the fundamental issue on which other ideals of equal power and opportunity hinge (Young 1990, 15-17). She does not deny that distribution of resources and material goods is important, but that the structures in place that determine how those distributions take place are the primary concern for an adequate theory of social justice.

Young's position takes on a fairly idealistic and utopian tone similar to that of Walzer in that she at once acknowledges and dismisses that higher incomes tend to buy better positions and more decision-making power by basically saying this "shouldn't" be the case (Young 1990,19). But if it is the case, how can one construct a theory of social justice without addressing it?

Young rightfully wants to question both the justness of distribution and the justness of the decision-making structures and institutions that determine distribution (Young 1990, 22). But she also wants to engage, like Walzer, in "the naming of the goods, the giving of meaning, and the collective making," which may be an interesting exercise, but fantasizing about what money ought not buy and what spheres of life it ought not rule is not very helpful in the creation of just systems and institutions (Young 1990, 22). Certainly it is more productive to acknowledge what money does buy and what spheres of life it does rule in considering what basic structures and systems should be in place to see that it may not overstep its bounds. Clearly, in theory as well as practice the answer includes some sort of equalizing mechanism. 
Young wants to say that opportunities are not an issue of distributive justice because whether or not there is justice of opportunity is not dependent upon distributive outcome but upon the social structures that allow for or inhibit opportunity (Young 1990,26). But this is to ignore that even when institutions are structured in a way to theoretically honor equality of opportunity, those with excessive wealth are able to purchase opportunity and those without are not.

Young's difference politics fails in an important regard. She demonstrates the recognition that oppression based on race is deeply rooted in capitalist structure. Even rightly stating, "Racism, like sexism, is a convenient means of dividing workers from one another and legitimating the superexploitation and marginalization of some" (Young 1990,122). The problem with her argument is that if she carried it through to its logical conclusion she would find that the issue at hand is class discrimination, with racism being a handy way of dividing loyalties among the underclass for those in positions of economic privilege who seek to maintain the status quo. Young is not wrong that racism exists or that it's an instrument of oppression, but her argument doesn't acknowledge that an African American like Michael Jordan may have lame jokes made about him by unenlightened racist people, but he is not vulnerable to the abuse, exploitation and oppression that, for example, an uneducated African American gas station attendant in the inner-city is. Racism is unpleasant but it is hard to place as the primary instrument of oppression in capitalist society. Capitalism exists and thrives in both racially diverse and homogenous environments (ie. US, Norway, Japan, England, Singapore). 
One might argue against this by pointing out that economic upward mobility is more challenging for some due to racism, sexism and the like - this is a valid criticism of the argument in this paper that could be made by feminist and multiculturalism theorists. It appears to be true that a poor and uneducated white man in the United States may have an easier time of transcending his background than white women and all people of color. It is beyond the scope of this paper to address that issue, but even if it is likely to be true, the argument that all people in capitalist society, regardless of race and gender, have greater access to education, opportunity and political power if they are born into or manage to accumulate excessive wealth is still valid. Therefore a theory concerned with social justice must include a means for preventing vast inequalities of wealth. As pointed out at the beginning of this paper, race and gender do still seem to impact the likelihood of being at the bottom of the economic barrel in the United States, but that fact strengthens the argument here that if wealth were redistributed according to class, not race, all would be better off. The problem of racism will likely still exist, but on the other hand, maybe race relations would dramatically improve without economic hardship, which leads people to look for a scapegoat for their misfortune. Brian Barry will shed more insight on that issue in the following pages.

Where Rawls, Walzer and Young all seem to agree is that, as Young states, “... social justice concerns the degree to which a society contains and supports the institutional conditions necessary for the realization of these values," where "these values" are competing definitions of good in a pluralist society (Young 1990, 37). This is, despite the bristling of Young against liberalism, a decidedly liberal ideal. 
The problem that all of their analyses fail to resolve, however, is that the degree to which this can occur is dependent upon the empowerment of all people in a pluralist society to live their values and those individuals who are on the bottom of the economic ladder are not afforded the same opportunity and freedom to direct their lives as are those at the top.

Brian Barry's Argument that Social Justice Hinges upon Equal Distribution of Material Goods

Building upon the work of John Rawls and accepting Rawls' notion of a "basic structure" created for the purpose of distributing social goods as a fundamentally good start in the quest for social justice, Brian Barry attempts to tackle the issue of economic disparity as it relates to social justice, asserting most importantly that while the creation and maintenance of just institutions is important, the concern of social justice is the analysis of the outcomes such institutions allow or produce (Barry 2005, 16-17). The focus of this paper is similarly concerned - if we are applying a theory to a liberal culture and the theory allows for vast income inequality, while empirical evidence asserts that vast economic inequality has a strong correlation with political inequality and inequality of opportunity, then we have a theoretical dilemma.

Where Young and Walzer assert that self-esteem is independent of economic standing, Barry recognizes that the "failure" implicit in poverty is demeaning in itself, whether or not there is racism or anything else attached to it (Barry 2005, 78). 
Barry is sensitive to racism and does see it posing a hindrance to just outcomes, but more often than not, where there is race discrimination, there is simultaneous class discrimination. For instance, he illustrates the disproportionate rate at which black drug offenders are convicted and imprisoned, but not only are they black, they are assigned public defenders because they are also too poor to purchase legal help. The criminal justice system is racist, but as Barry mentions for a different purpose, OJ Simpson was acquitted (Barry 2005, 96-97). Barry doesn't state this directly, but African-Americans who have money are treated better by the criminal justice system then are those who do not. ${ }^{5}$

Using the privatization of prisons as an example Barry illustrates how the criminal justice system exploits the poor and benefits the rich. Those who are benefitting from the privatization of prisons are making money and donating it to political candidates who enact policies that will serve to imprison even more people. Meanwhile the victims of these policies have no financial clout and if they have been in prison they can't even exercise their fundamental right of citizenship by voting (Barry 2005, 102-103).

In contrast with drug offenders who tend to operate on the bottom of the economic scale, Barry shows that wealthy committers of crime involving great theft and such more often than not go largely unpunished (Barry 2005, 104). Part of the reason for this is the ability to purchase legal help and another reason Barry suggests is that the wealthy are looked upon as harder working, better, smarter,

\footnotetext{
${ }^{5}$ The criminal justice issue is beyond the scope of this paper to research or analyze, but an intuitive and anecdotal argument could be made that the economically advantaged fare better regardless of race.
} 
etcetera people than are the poor - the poor are disposable in a capitalist economy, the wealthy keep things running properly (Barry 2005, 104).

Perhaps the most disturbing outcome of wealth inequality is the variance in IQ among wealthy and poor children (Barry 2005, 122). Not to lend too much credence to IQ tests, but as they serve as one measure of basic cognitive ability and future academic success as culturally defined, it is clear that simply by virtue of being born into wealth one's reasoning abilities develop better, if not objectively speaking, at least better in a manner that predicts success in a particular culture. Barry shows that the notion of "native intelligence" is unreliable at best. That alone is enough to prove that economic inequality un-levels the playing field of alleged equal opportunity, by definition, and it perpetuates a false notion that some people are born smarter than others without regard to their early socialization (Barry $2005,135)$. In sum Barry argues that the meritocratic view of social justice is erroneous because environment so heavily influences even genetic predisposition therefore denying opportunities to some based on a perceived notion of lack of innate ability is a severe injustice, because without the opportunity there is no way to know what the level of ability actually could be (Barry 2005, 126-127).

Another prejudice about poor people, particularly in American society, that Barry discusses is the rags-to-riches ideal - the idea that the hardworking and responsible can overcome their economic misfortune and become inordinately wealthy (Barry 2005, 140-141). Indeed the very notion of the "American Dream" rests on this assumption. But for a variety of reasons discussed here, just because someone can rise out of poverty, allegedly the result of nothing but his own 
ingenuity, it does not follow that anyone can do it. Further, it would be difficult to argue that the wealthy person who inherits a position at his family's corporation has "worked harder" a day in his life than say a migrant farm worker or coal miner. For most people extremely hard work is the road to barely getting by, not riches.

Another important hole in previous notions of social justice that Barry fills is the evidence highlighting welfare laws and public perception of welfare's purpose. Laws are frequently enacted that further needle those getting by at the subsistence level in order to defend the "rights" of those who have more than they need to keep what they have (Barry 2005, 152). The primary problem this creates for the purpose of social justice and further evidence that there is no social justice in the presence of disparate wealth distribution, as well as further evidence that minimal standard welfare states do not satisfy the goals of social justice, is that it clearly reveals a lack of political power of those living in poverty by virtue of their living in poverty. This poses a problem for the idea that citizens should be treated with equal concern as argued by Ronald Dworkin, whose ideas will be examined more closely in the next section.

This focus by politicians on the few rags-to-riches stories or the few welfare cheats and so on is something Ian Shapiro has labeled "anecdotal distraction," and it appears to be a highly effective means of protecting the status quo and promoting agitation among the lower and middle classes. It also manifests itself as making an example of someone among the elites who actually gets punished for committing a crime and by lauding those on welfare who transition into successful workers (Shapiro 2003, 131-133). 
Barry also addresses the ideal in American culture that individuals are responsible for their own choices. "Corporations spend a lot of money on promoting the 'personal responsibility' approach, while being at the same time acutely conscious of their ability to manipulate individual choices and suppress information that is essential to responsible choosing" (Barry 2005, 154). This illustrates another example of the very wealthy exerting domination over the masses and profiting from their lack of power, information and/or choices.

Barry also addresses politics of identity and concludes, just as was posited earlier in this paper, that more often than not, racism is the result of scapegoating a particular ethnic group due to economic issues and the fueling of this kind of racism prevents the underclasses from achieving the necessary solidarity to fight back against the actual oppressor, which he calls "the rich" (Barry 2005, 182). There is much evidence of this in the current Mexican/American immigration debate - much is made of the so-called racism of the poor white Americans who fear losing what little they have to migrant workers, when in reality, they and the migrant workers are victims of the same exploitation with only differing levels of severity. It serves the employers of these workers if they are fighting amongst each other over something as arbitrary as race rather than recognizing the injustice in their collective economic positions. Among the middle class this is an issue for affirmative action, which determines who gets promoted and such - this bickering about race detracts from the overall decreasing earning power and benefits enjoyed by all workers (Shapiro 2003, 128). 
Political inequality doesn't only manifest in individuals as a result of individual economic inequality - on a larger scale, political parties that are established and have wealthy members succeed in suppressing alternative political ideas and candidates that don't fit within the current political box by denying them the funds, media exposure and more generally basic legitimacy necessary to compete politically (Barry 2005, 239). Wealthy organizations can more efficiently direct political policy, as can wealthy individuals, who already have exponentially greater political clout as illustrated in the earlier section regarding oligarchy.

Barry ultimately tries to imagine what a just world would look like, without being utopian - a seemingly futile endeavor in the field of political theory - and concludes rightly that one thing a just world must do is "approximate material equality" (Barry 2005, 216). He does offer some feasible ideas, not for how to distribute material goods, but what the economic and social costs of avoiding disparate wealth might be - he asserts that people would be healthier and there would be less crime among other things. Ultimately he suggests that while some things would cost money (to be raised in the form of taxes) that costs would be saved as well (Barry 2005, 220-222). In the end, he asks not if we can afford the costs of creating a just society, but if we can afford not to promote social justice by virtue of tempering the degree to which greed is rewarded (Barry 2005, 229). 
Conclusion

All of the works referenced in this chapter presume a more or less capitalist society with substantial economic inequality. Some of the authors appear to favor varying degrees of socialist ideals (particularly Michael Walzer), but none of them question whether economic inequality is simply unjust in and of itself, with the exception of Brian Barry, a self-proclaimed Democratic Socialist. They all seem to seek a way to render the structures already in place "more fair and just" rather than to revolutionize them, and the societies they happen to reference operate under a degree of capitalism. Capitalist economics rewards greed and vast inequalities of wealth accumulation are intrinsic to its nature. It presumes, by definition, that a segment of the population will not be able to obtain as much material resources as it needs - hence the invention by humanitarians of welfare capitalism. It further goes without saying that in a liberal political culture that holds individualism, autonomy, liberty and equality as human virtues that those people at the bottom will be blamed and abused for their lack of ability to provide for themselves.

But according to Ronald Dworkin this need not be the case. Indeed he claims, “an egalitarian economy is a basically capitalist economy" (Dworkin 2011, 357). Dworkin argues that free markets require regulation in order to ensure that the cost of goods reflects the true opportunity cost of producing those goods - that in the spirit of equal concern there needs to be protection against monopolies and other such things that distort an unregulated market (Dworkin 2011,357). The second problem with the free market according to Dworkin, is not as simple to resolve, nor 
is it as simple to understand. According to Dworkin's "envy test," which is applied after all theoretical members, who have theoretically begun with equal resources are left free to pursue their own interests, the person who chose to be a poet will not be envious of the person who chose a more economically advantageous path, because not everyone prioritizes accumulating wealth. However, the envy test can fail in the free market, Dworkin argues, when responsible investments nevertheless don't end well or individuals fall ill or injured or lack the specific talents that are economically viable in a particular place and time, or other such situations in which a person hasn't chosen his economic outcome, but is stuck with it nonetheless (Dworkin 2011,357). Dworkin is opposed to erasing the consequences of bad luck on the grounds that it undermines personal responsibility, which is an essential ingredient of his position on ethics (Dworkin 2011,358). However, he does devise an elaborate hypothetical insurance scheme that looks an awful lot like welfare capitalism in the end, complete with unemployment insurance and social security and the like (Dworkin 2011, 359-361).

Michael Walzer's assertion that all basic needs should be met is admirable toward the goal of being compassionate, as is Dworkin's notion of more or less a safety net for those who fall to bad luck, but both are inadequate for creating a just distribution of resources. Even Rawls acknowledges that satisfying basic human needs does not satisfy the requirements of a free and equal citizenry. It does address people's fundamental needs but does not address their marginalization, exploitation, vulnerability to abuse or lack of political voice as compared with those who have far more resources than they need. Rawls' difference principle attempts 
to always better everyone's position but it does not address that one group becoming marginally better off while another group becomes infinitely better off necessarily upsets the balance of political power and also therefore the basic principles of justice he holds as constitutional essentials (Barry 2005, 173). Iris Marion Young's desire to see a world in which economic inequality is not important is simply utopian and the Libertarian viewpoint that justice rests in protecting the rights of the strong and clever over providing for the needs of the weak and less gifted is grossly inhumane and not conducive to the shared purpose of social life and the implied reciprocity of civil society.

Wealth is not just a social good among many. Money is used in capitalist society to purchase education, opportunity and power at all social and political levels - whether it "should" or not. An effective theory of social justice must accept this as a given within a capitalist economy and explore the means by which distribution of resources can both occur fairly and generate a fair and just outcome immediately and over time. It may be that capitalist economics, however regulated, is not conducive to this end, but in sum any economic system (or lack thereof) that allows for vast economic inequality is, by definition, unjust. 


\title{
Chapter 4
}

\section{Revised Social Justice Theory}

\begin{abstract}
In Chapter 4 a political solution is proposed after acknowledging that this paper has set up the current crisis for social justice in the United States as a politically created issue. Chapter 4 builds upon the theories critiqued in Chapter 3. Presuming at this point that economic inequality is, in fact, a threat to political liberty and equality of opportunity, a remedy is proposed that suggests that the best way to deal with the problems created by vast economic inequality - defined as the current condition in the United States in which $.001 \%$ of the population controls $80 \%$ of the wealth - is simply to not allow for it.
\end{abstract}

The crisis for social justice facing the United States today was created through the political process; therefore political theory is a proper method to explore a solution. As Ronald Dworkin points out, an individual's economic resources depend only, in part, on his choices, and, in part, on government's choices. For example, Laissez-faire economics does not mean "without government interference," rather it means government makes one set of laws in lieu of another (Dworkin 2011, 353-354). The same could be said of progressive era laws. As we have seen, current American laws tend to benefit some at the expense of others over time and do not, therefore, treat individuals with equal concern. In this chapter I will propose an alternative perspective on balancing liberty and equality in a contemporary capitalist economy, because as Brian Barry argues that if we are concerned about equal rights, "we should also be concerned about equal opportunities to exercise those rights" (Barry 2005, 25).

Some of the possible solutions derived from this analysis are not very far from the policies already favored in American culture, while others are radical 
departures, but all are compatible with a liberal political culture. In this chapter I will focus on proposing immediate "minimal steps," following Dworkin, who argues that in order for a theory of distributive justice to be useful, it should have minimal steps that can be taken immediately as steps in the right direction and need not create utopian theories (Dworkin 2011, 352).

I propose the following four steps to moderate economic inequality as a means to moderate political inequality. Presuming as true Brian Barry's claim that social justice requires tempering the degree to which greed is rewarded, my suggestion accepts Walzer's proposal for a minimum standard but insists that it be universal and not means tested - ensuring certain goods are provided to all not as welfare but as a public good. I also supplement Walzer's theory by adding a ceiling for wealth accumulation. On the topic of inheritance, I will build onto Rawls' theory of taxation of inherited wealth by setting an absolute cap on the provision of inherited wealth as well. Regarding equalizing the income gap I propose a revised minimum wage and revised income tax scheme that disproportionately burdens high earners and corporations.

Below I defend and place these ideas within the context of contemporary and modern political theory.

\section{Minimum Standard}

Some of the work examined in this paper advocates for a minimum standard of basic welfare due citizens, which while admirable, does not meet the requirements of social justice as articulated by the paper. The notion that 
everyone's basic needs should be met still suggests that the person with more is more entitled to have more, but ought to be generous enough to provide for those who are not necessarily deserving - essentially a welfare model. Echoing Rousseau I suggest, "You are undone if you once forget that the fruits of the earth belong to us all, and the earth itself to nobody" (Rousseau 1993, 84). I propose that while some labors, goods or services may be more valuable in the monetary sense, that none are so valuable that one or a few people among us should be controlling excessive amounts of wealth while others are impoverished. The welfare capitalist state that John Rawls is willing to accept as just may offer humans the bare minimum to sustain life but it does not acknowledge equality of dignity or equality of the right to live in a dignified fashion by virtue of being a member of a civil society. Walzer touches on this, suggesting that distributive justice addresses both need and "membership" in society, and it is not only necessary to address people's most basic needs, it is also important to provide the goods necessary to "sustain their membership" (Walzer 1983, 78). For these reasons, following Brian Barry I propose that the minimum standard must be universal as opposed to means-tested (Barry2005, 218). This standard could be implemented on an ad hoc and evolutionary basis by slowly implementing more and more minimum standards encompassing basic needs for both survival and ensuring equal opportunity. For example, providing over time free levels of education, housing, utilities, internet access, food, health care, elementary and advanced education, etcetera in an order 
and timing that is politically viable or otherwise desirable. ${ }^{6}$ This is a less polarizing way of looking at equalization of resources.

Wealth Tax and Cap

The theorists analyzed in this paper, other than Rousseau, appear to ignore the problems of wealth accumulation. Rawls' theory doesn't provide any limit on the accumulation of wealth as long as the difference principle is satisfied. However, even when the difference principle is satisfied disparate wealth accumulation is problematic because of its tendency to lead to political inequality. As Brian Barry argues, some people become relatively worse off, even if their economic position hasn't changed for the worse, because others' positions have changed for the better, leaving the first group absolutely worse off (Barry 2005, 173). If we alter our perspective from "it shouldn't matter" because political equality must precede the difference principle to "it does matter" because that is the nature of a capitalist economy, then Rawls' conclusion that there need not be limits on wealth accumulation are undermined. A limit seems rightly imposed to obtain the goals that Rawls is arguing for - political equality and equality of opportunity.

\footnotetext{
${ }^{6}$ What exactly the minimum standard should be or how it should be determined is unfortunately beyond the scope of this paper to address, but it should reflect a concern for human dignity and a respect for the importance of the opportunity to develop one's talents and pursue one's goals, if born into the situation of having nothing more than the minimum standard.
} 
Similarly, Walzer argues that wealth accumulation should not matter as long as all citizens have a minimum standard (their basic needs met) and as long as money cannot buy important things such as opportunities, education, political office, etc. Again, in the absence of restrictions that unequivocally ensure that money cannot buy important things, imposing limits on wealth disparity will help to ensure that money cannot operate outside its sphere. Walzer's view that money should not operate outside its sphere is sound and may be a workable theory in some economic structures, but in a capitalist economy, excessive wealth does not only afford one the ability to purchase a few more trinkets and widgets, but also threatens political equality. It's critical that a social justice theory recognize the danger massive wealth accumulation poses to political inequality and equality of opportunity. Walzer's assertion that inequality of wealth need not be problematic because money ought not buy certain goods such as political power is noble, but there is too much evidence that, as Rousseau pointed out, there is danger to the notion of political power when wealth inequity is so great that one person can effectively purchase another for us to simply leave Walzer's theory where it stands. Empirical evidence indicates that money does and will operate outside its preferred sphere of influence and it is therefore useful to attempt to construct a theory that begins with that assumption.

As such, a constitutional amendment to allow for the direct taxation of wealth, as well as to impose an absolute cap on wealth accumulation is a step in the 
right direction. ${ }^{7}$ The excess accumulated wealth can then be used for the common good by providing benefits such as food, housing, education, medical care and other goods necessary for the purpose of social justice theory.

\section{Inheritance Tax and Cap}

I propose that strict limits be placed on inheritance using an absolute cap on the amount of inheritable wealth. This is a result of my analysis in chapter three that inheritance does not meet the criteria of the difference principle as well as my agreement with Brian Barry that vast wealth inequality is the "great enemy of social justice," and inheritance does nothing but continue and increase wealth inequality with the greatest of ease.

Rawls explores a little bit about limiting wealth accumulation through various possible taxation strategies - inheritance and progressive income tax to prevent the tendency for the difference principle to create wealth allocations that are "inimical to background justice" (Rawls 2001, 160-161). Walzer views inheritance as a special form of gift-giving and does not appear troubled by it so long as it is a commodity or money and has no "power" attached to it (Walzer 1983, 126-128). Dworkin argues for an inheritance tax progressive and high enough to avoid stratification, and posits using the tax for public education and other programs that ease the stratification that remains. (Dworkin 2000, 349). Dworkin's

\footnotetext{
7 There is a problem with this solution - as Brian Barry points out, the obvious reason this is not generally done is that if the state takes back too much of people's wealth, the wealthy will simply take their capital to a more capital friendly state (Barry 2005, 192). The ideal (and impractical) way of addressing this is to hope it might be an international policy. Absent that, an exorbitant exit tax and renounced citizenship rights could curb attempts to circumvent this policy.
} 
desire to avoid stratification is important for social justice, and a possible way to avoid stratification is to simply impose a cap on the amount of wealth that is inheritable.

In theory, as Dworkin argues as well, given equal opportunity, some people will value higher pay and others will value something other than making as much money as possible. Unequal income distribution is not problematic for social justice theory in itself, which is why graduated income tax and minimum wage reform are only small parts of the solution posited by this thesis. What is problematic is the unchecked accumulation of wealth over time through inheritance, the greatest benefits of that wealth being to those who never worked a day to earn it, while others who did not happen to win the "birth lottery" work hard for scarce reward. While the liberal tradition (and certainly American political culture) may bristle at this perceived attack on property rights, this is a good point at which to remember that property rights are not the only rights that matter - and social justice demands that the right of all to accumulate and inherit wealth be balanced with the right of all to be treated as a fair and equal citizens.

Minimum Wage/More Progressive Income Tax

Another important element of social justice, as all of the philosophers examined here, with the exception of Nozick, point out, is a minimum standard, and a minimum wage and more progressive income tax comport with this goal. As pointed out above, above a minimum standard of welfare by itself is not compatible with the goals of social justice theory as set forth in this paper. It's important in 
American political culture that a minimum standard be rights-based as well as universal, whether that be the best way to frame the issue or not. ${ }^{8}$ One way to facilitate a minimum standard that is compatible with a notion of equality of inherent dignity, as was mentioned earlier, is to tie the minimum wage to the average wage (including executive compensation) and to ensure that minimum wages keep pace with inflation. This is critical and should be agreeable even to libertarians, if in fact they are concerned with individuals' ability to freely enter into a contract. Too many people too desperate for work is a recipe for unfair labor negotiations; therefore there is no sound liberal argument for allowing it.

Additionally, it is a way to ensure a minimum standard that is not confused with the notion of welfare, as in the wealthy "giving something to" or "doing something for" the poor, which is an affront to human dignity. This is especially an appropriate remedy to propose for the United States because it redistributes wealth in a way that does not burden government directly and is connected to work, therefore it is likely to appeal to the average voter in American political culture (Shapiro 2003, 115). In fact, as illustrated in chapter one, the majority of Americans do support a more progressive minimum wage. Protecting the rights of all citizens by equalizing their bargaining positions and protecting their equality of opportunity satisfies the goals of liberalism, ethics and social justice at once.

\footnotetext{
${ }^{8}$ Some theorists such as Elizabeth Wolgast make a strong argument that thinking about all social goods in terms of "rights" may be a hindrance to thinking about social justice. And certainly following Ronald Dworkin and others, social justice could be analyzed in the simple language of ethics. But for the purpose of this paper, we're not going to re-invent the fundamental nature of the controversy as it occurs in the contemporary United States - the argument for distributive justice is perfectly strong using a a rights-based approach.
} 
Progressive income tax is another method of equalizing incomes, but most importantly, income tax should be structured in a way that heavily burdens excessively high wage earners (like CEOs), capital gains, stock options (when offered in lieu of direct monetary compensation), interest income, dividend income and corporate profits, as opposed to simply burdening small business owners and moderately high wage earners such as doctors. As demonstrated in chapter one, there was a time when corporations provided more federal revenue and payroll taxes provided less - there is no rational reason to not return there. 


\section{Conclusion}

We began this paper by examining the findings of the American Political Science Association and questioned their conclusion that vast income disparity may be implicated in political inequality - defined as people's power to create and amend policies that affect them. It appears from the research subsequently conducted and analyzed in this paper that income inequality is indeed implicated in political inequality, as well as inequality of opportunity. This in turn poses a problem for individual liberty - defined as the ability to direct one's own life and pursue the things that matter to him/her.

In chapter one we examined the empirical evidence supporting a correlation between economic and political inequality and inequality of opportunity. It was shown that the current levels of economic inequality appear to correlate, if not cause, substantial political inequality.

In chapter two we examined the importance of equality, the relationship between liberty and economic position, and the evolution of liberal thought on these issues. We found that equality matters, that individual liberty is largely dependent upon economic position, and that liberal thought has traditionally evaded the inherent conflict between economic and political equality.

In chapter three we examine how contemporary political theory has finally begun to address these issues after recognizing that economic equality matters for the purpose of social justice theory. We uncovered different opinions regarding the degree of inequality that can be tolerated for the sake of individual liberty and the 
conditions that render those degrees of inequality more or less just. I demonstrated that some income inequality must be tolerated in a culture that values liberty and autonomy, but that social justice requires that the gap between the richest and the poorest be narrow enough that it does not damage the prospects of the least well off or allow the advantaged to exert oppressive power over the less advantaged.

In chapter four I offered some solutions for correcting the level of wealth inequality that is the natural outcome of unregulated capitalism and has developed in the United States due to a series of economic policy revisions. I suggested most importantly that there should be a ceiling for wealth accumulation. An amendment to the constitution to permit or even require the taxation of accumulated wealth above a certain level, a cap on the amount of wealth that is inheritable rather than an increased estate or inheritance tax percentage, and to a lesser degree a greater graduated income tax could all work together to accomplish this end theoretically. I also suggested a universal minimum standard, including minimum wage reform. A just society can allow for some inequality of wealth, but not the degree to which it exists in the United States, and nothing perpetuates inequality more than the policy of allowing tremendous wealth to be inherited.

Further it appears that simple income inequality is not as dangerous in this regard as is accumulated wealth disparity. That one's station at birth best indicates his/her economic outcome in life is evidence of a de facto aristocracy in the United States and is a threat to the American ideal of liberty. To combat this trend is an important concern for political theory. Economic equality may not continually be 
subordinated to economic liberty if political equality and equality of opportunity matter. 
Works Cited

American Political Science Association. 2004. “American Democracy in an Age of Rising Inequality." Perspectives on Politics 2 (4): 651-666.

Barry, Brian. 2005. Why Social Justice Matters. Cambridge: Polity Press.

Bartels, Larry M. 2008. Unequal Democracy. Princeton: Princeton University Press.

Berlin, Isaiah. (Henry Hardy ed.) 2002. Isaiah Berlin Liberty. Oxford: Oxford University Press.

Constant, Benjamin. 1988. Political Writings. New York: Cambridge University Press.

Dworkin, Ronald. 2011. Justice for Hedgehogs. Cambridge: The Belknap Press of Harvard University Press.

Dworkin, Ronald. 2000. Sovereign Virtue. Cambridge: Harvard University Press.

Gelman, Andrew. 2008. Red State Blue State Rich State Poor State. Princeton: Princeton University Press.

Hacker, Jacob S., and Paul Pierson. 2010. Winner-Take-All Politics. New York: Simon \& Schuster Paperbacks.

Jacobs, Lawrence, and Desmond King. 2009. The Unsustainable American State. New York: Oxford University Press.

Kymlicka, Will. 1989. Liberalism, Community and Culture. New York: Oxford University Press.

Mill, John Stuart. 2010. On Liberty and Other Essays. Lawrence, KS:

Digireads.com, a subsidiary of Neeland Media LLC. 
Mill, John Stuart. 1848. Principles of Political Economy with some of their Applications to Social Philosophy, $7^{\text {th }}$ ed. London: Longmans, Green and Co. 1909. Retrieved Online from Library of Economics and Liberty. Nozick, Robert. 1974. Anarchy, State, and Utopia. New York: Basic Books, Inc. Rawls, John. 2001. Justice as Fairness: A Restatement. Cambridge, MA: Harvard University Press.

Rawls, John. 2005. Political Liberalism. New York: Columbia University Press. Rawls, John. 1971. A Theory of Justice. Cambridge: The Belknap Press of Harvard University Press.

Rivoli, Pietra. The Travels of a T-Shirt in the Global Economy: An Economist Examines the Markets, Power and Politics of World Trade. Hoboken: John Wiley \& Sons, Inc.

Rousseau, Jean-Jacques. 1993. The Social Contract and Discourses. London: Oriaon Publishing Group.

Sandel, Michael J. 2009. Justice: What's the Right Thing To Do?. New York: Farrar, Straus and Giroux.

Shapiro, Ian. 2003. The State of Democratic Theory. Princeton: Princeton University Press.

Walzer, Michael. 1983. Spheres of Justice: A Defense of Pluralism and Equality. New York: Basic Books Inc.

Winters, Jeffrey A., and Benjamin I. Page. 2009. “Oligarchy in the United States?." Perspectives on Politics. 7 (4): 731-751.

Wolgast, Elizabeth H. 1987. The Grammar of Justice. Ithaca: Cornell University 
Press.

Young, Iris Marion. 1990. Justice and the Politics of Difference. Princeton: Princeton University Press. 